\title{
Nanospheres Prepared by Self-Assembly of Random Copolymers in Supercritical Carbon Dioxide
}

\author{
Eri Yoshida \\ Department of Environmental and Life Sciences, Toyohashi University of Technology, 1-1 Hibarigaoka, \\ Tempaku-cho, Toyohashi, Aichi 441-8580, Japan \\ Correspondence should be addressed to Eri Yoshida, eyoshida@ens.tut.ac.jp
}

Received 19 August 2011; Accepted 28 November 2011

Academic Editor: Takashi Kaneko

Copyright ( 2012 Eri Yoshida. This is an open access article distributed under the Creative Commons Attribution License, which permits unrestricted use, distribution, and reproduction in any medium, provided the original work is properly cited.

The synthesis of spherical particles was attained by the direct self-assembly of poly[2-(perfluorooctyl)ethyl acrylate-random-acrylic acid], $\mathrm{P}(\mathrm{POA}-r$-AA), and by the indirect self-assembly poly[POA-random-2-(dimethylamino)ethyl acrylate], $\mathrm{P}$ (POA- $r$-DAA), with dicarboxylic acids in supercritical carbon dioxide $\left(\mathrm{scCO}_{2}\right)$. The copolymers formed spherical particles with hundreds of nanometer diameters in a heterogeneous state at pressures lower than the cloud point pressure. The formation of spherical particles was also dependent on the temperature. The formation of spherical particles could be optimized through varying the solvent quality by the manipulation of the $\mathrm{CO}_{2}$ pressure and temperature for the different copolymer compositions. The dynamic light scattering and ${ }^{1} \mathrm{H}$ NMR studies demonstrated that the nanospheres had the micellar structures consisting of the $\mathrm{CO}_{2}$-philic POA shells and the $\mathrm{CO}_{2}$-phobic AA or DAA cores including the main chain cores. The nanospheres produced the superhydrophobic surfaces based on the water-proof shells of the POA units.

\section{Introduction}

Micro- and nanosized polymer particles have many industrial applications, such as coating [1], painting [2], cosmetics [3], adhesives $[4,5]$, and drug carriers $[6,7]$. These spherical particles are often prepared by heterogeneous polymerizations of suspension polymerization $[8,9]$, dispersion polymerization [10-12], and emulsion polymerization [13-15]. While such heterogeneous polymerizations have merits in the simple procedure and particle size control, the polymerizations include problems in taking dozens of hours to produce spheres and disposing the waste solvents.

Molecular self-assembly is also important to prepare spherical particles and has advantages over the heterogeneous polymerizations in the spontaneous and environmentally benign reactions through noncovalent bond interaction. The self-assembly in supercritical carbon dioxide $\left(\mathrm{scCO}_{2}\right)$ has both the benefits combining its energy-saving reaction and its environmental benefits of being nontoxic, odorless, spontaneous, and volatile. The benefits also include the industrial utilities of being recyclable and having mild critical conditions $\left(31.1^{\circ} \mathrm{C}, 73.8\right.$ bar $)$. There have already been publications on the self-assembly in $\mathrm{scCO}_{2}$; the micellization of block copolymers, such as polystyrene-block-poly $(1,1-\mathrm{di}$ hydroperfluorooctyl acrylate) [16], poly(vinyl acetate)-blockpoly(1,1,2,2-tetrahydroperfluorooctyl acrylate) [17], poly (vinyl acetate)-block-poly(1,1-dihydroperfluorooctyl acrylate) [18-20], and poly(2-hydroxyethyl methacrylate)-blockpoly(1,1-diethylsilabutane) [21], and the self-assembly of surfactants, such as ammonium carboxylate perfluoropolyether [22], bis $(1 \mathrm{H}, 1 \mathrm{H}, 5 \mathrm{H}$-octafluoro-n-pentyl) sodium sulfosuccinate, and the hybrid di-chained sulfate [23]. The self-assembly of these block copolymers and surfactants in $\mathrm{scCO}_{2}$ produced spherical micelles having the perfluoroalkyl or alkylsilyl shells and the hydrocarbon or ionic cores (Scheme 1).

We found a novel and convenient method to prepare nanospheres through the direct and indirect self-assembly of random copolymers in $\mathrm{scCO}_{2}$ [24-26]. This paper 


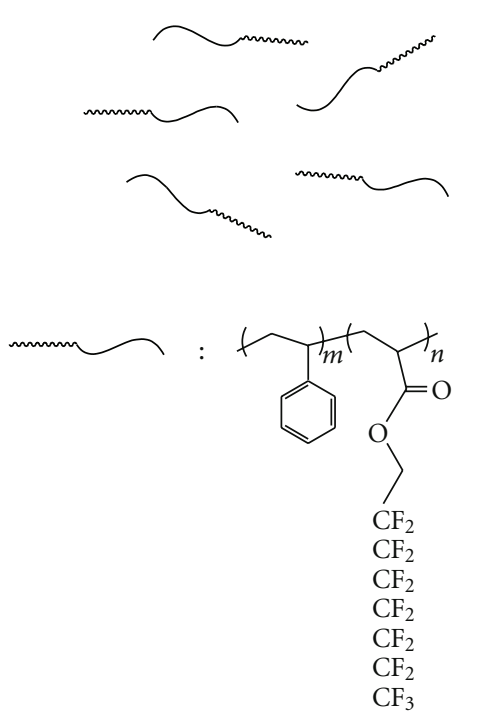

[16]<smiles>CC[Si](C)(CC)CCCC1CCC(C)(C)C1OCCO</smiles>

[21]

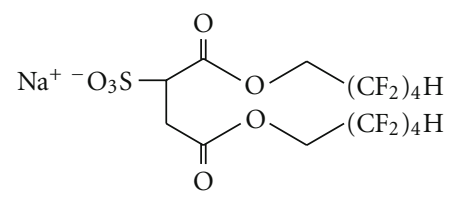

[23]
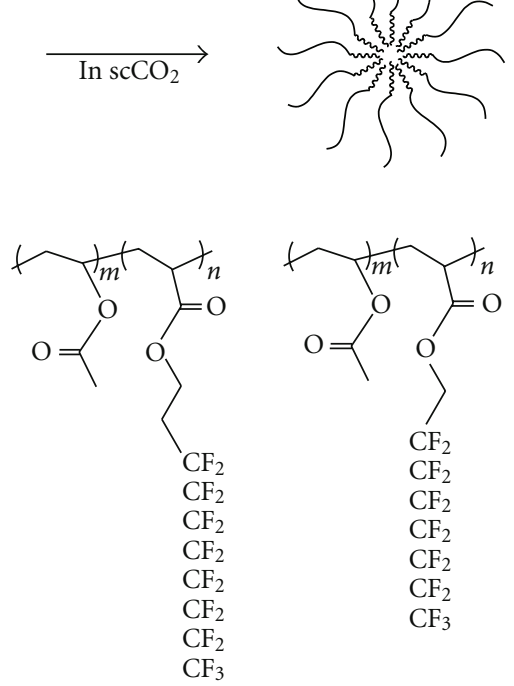

[17]

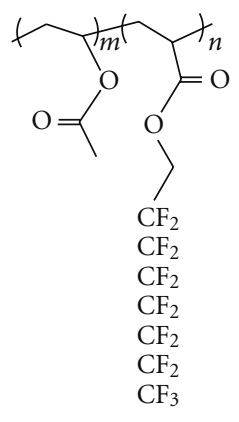

[18-20]

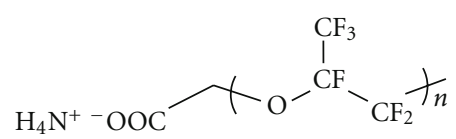

[22]

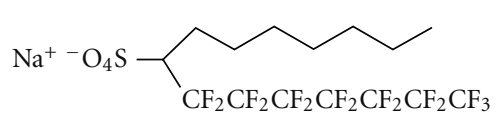

[23]

Scheme 1: The self-assembly of the block copolymers and surfactants in $\mathrm{scCO}_{2}$.

TABle 1: The P(POA-r-TBA) copolymers.

\begin{tabular}{lccccccc}
\hline \multicolumn{2}{c}{ Feed ratio } & \multirow{2}{*}{ Time (min) } & Yield (\%) & \multirow{2}{*}{$M n^{\mathrm{a}}$} & \multirow{2}{*}{$M w / M n^{\mathrm{a}}$} & \multicolumn{2}{c}{ Composition $^{\mathrm{b}}$} \\
POA & TBA & & & & & \multicolumn{2}{c}{ POA } \\
\hline 0.90 & 0.10 & 30 & 91 & 66,000 & 6.77 & 0.89 \\
0.80 & 0.20 & 45 & 88 & 78,000 & 6.16 & 0.80 \\
0.70 & 0.30 & 120 & 88 & 72,000 & 5.91 & 0.67 \\
0.60 & 0.40 & 40 & 52 & 57,000 & 6.78 & 0.60 \\
\hline
\end{tabular}

${ }^{a}$ Estimated by GPC based on poly(methyl methacrylate) standard.

${ }^{\mathrm{b}}$ Estimated by ${ }^{1} \mathrm{H}$ NMR.

describes the preparation of nanospheres by the selfassembly of random copolymers containing the $\mathrm{CO}_{2}$-philic 2-(perfluorooctyl)ethyl acrylate (POA) units.

\section{Materials and Methods}

2.1. Instrumentation. The ${ }^{1} \mathrm{H}$ NMR measurement was conducted using a Varian 300 FT NMR spectrometer. The gel permeation chromatography (GPC) was performed using a Tosoh GPC-8020 instrument equipped with a DP-8020 dual pump, a CO-8020 column oven, and an RI-8020 refractometer. Two polystyrene gel columns, Tosoh TSKgel $\mathrm{GMH}_{\mathrm{HR}}-\mathrm{M}$, were used with hexafluoroisopropanol (HFIP) as the eluent at $40^{\circ} \mathrm{C}$. The cloud point measurements were performed with a Nekken variable volume view cell (with a window made of tempered glass) equipped with an Eyela 


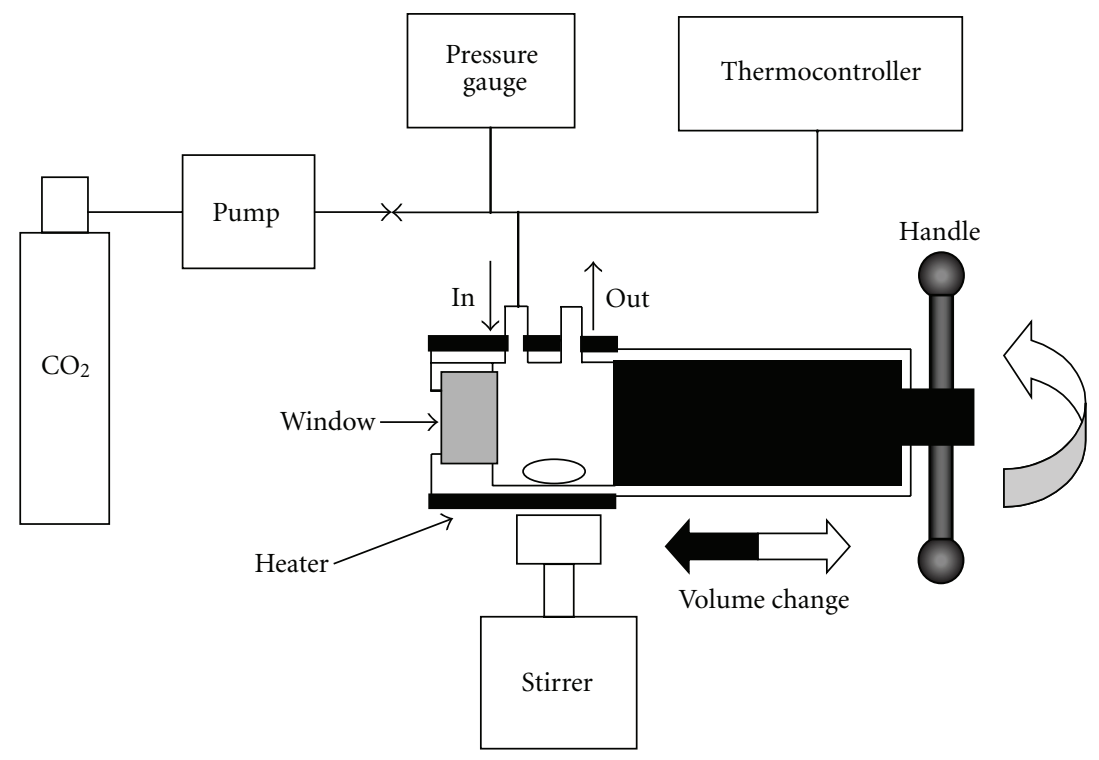

Scheme 2: A schematic of the experimental variable volume view cell.

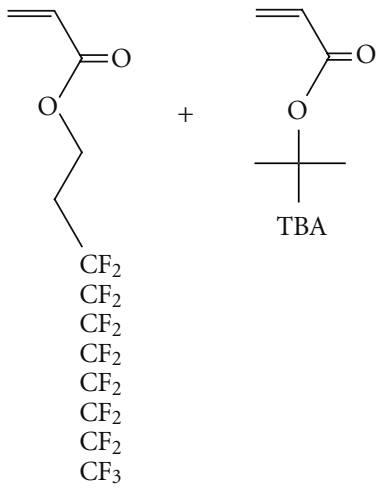

POA

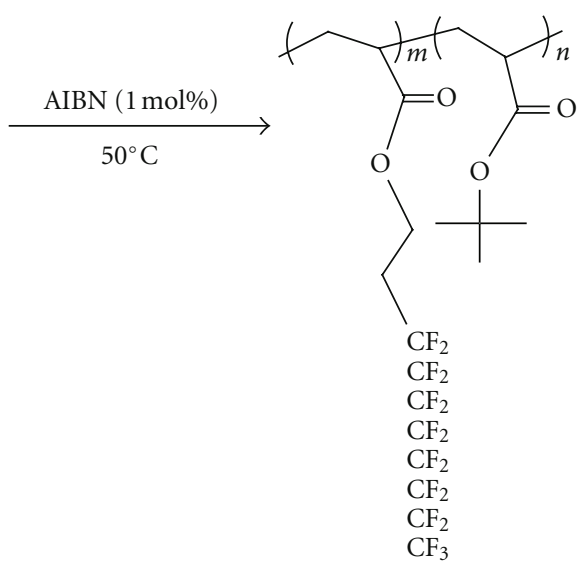

$\mathrm{P}(\mathrm{POA}-r$-TBA $)$

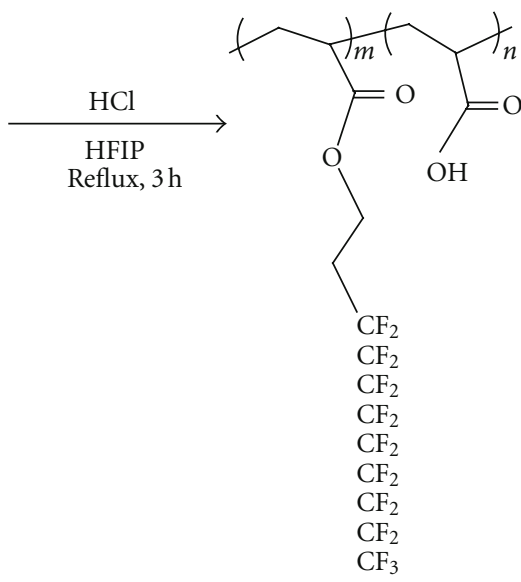

$\mathrm{P}(\mathrm{POA}-r-\mathrm{AA})$

Scheme 3: Synthesis of P(POA- $r$-AA). 


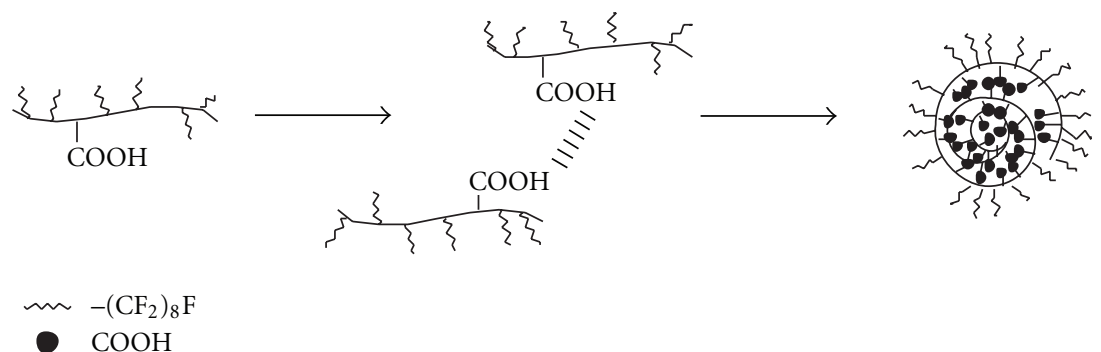

Scheme 4: A schematic of the formation of the spherical particles.

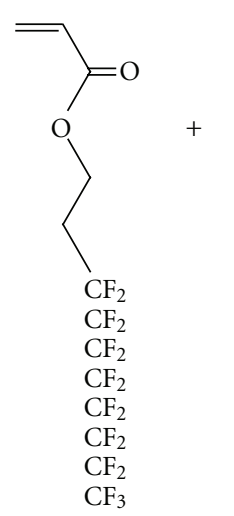

POA<smiles>C=CC(=O)OCCN(C)C</smiles><smiles>CCCCCCCCCCCCC</smiles>

DAA

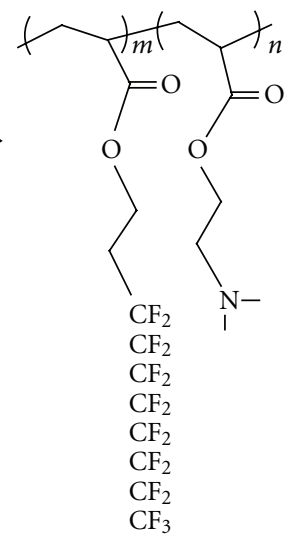

$\mathrm{P}(\mathrm{POA}-r-\mathrm{DAA})$

SCHEME 5: Synthesis of the $\mathrm{P}(\mathrm{POA}-r$-DAA) random copolymers.

TABLE 2: The P(POA-r-AA) copolymers.

\begin{tabular}{lcccc}
\hline \multicolumn{2}{c}{ Composition } & \multirow{2}{*}{ Yield (\%) } & M $n^{\mathrm{a}}$ & Sample name \\
POA & AA & & & \\
\hline 0.89 & 0.11 & 84 & 110,000 & $9 / 1$ \\
0.80 & 0.20 & 98 & 97,000 & $8 / 2$ \\
0.67 & 0.33 & 89 & 72,000 & $7 / 3$ \\
0.60 & 0.40 & 98 & 84,000 & $6 / 4$ \\
\hline
\end{tabular}

${ }^{a}$ Estimated by GPC based on poly(methyl methacrylate) standard.

TABle 3: The P(POA-r-DAA) copolymers.

\begin{tabular}{lccc}
\hline POA/DAA & $M n^{\mathrm{a}}$ & $M w / M n^{\mathrm{a}}$ & $\operatorname{Tm}\left({ }^{\circ} \mathrm{C}\right)$ \\
\hline $9 / 1$ & 58,000 & 10.95 & 60.3 \\
$8 / 2$ & 55,000 & 8.37 & 55.3 \\
$7 / 3$ & 50,000 & 7.35 & 47.8
\end{tabular}

${ }^{a}$ Estimated by GPC based on poly(methyl methacrylate) standard.

CCA-1110 cooler and a Nihon Seimitsu Kagaku NP-D-321 personal pump. The scanning electron microscopy (SEM) measurements were made using a JEOL JSM-6300 electron microscope. The Pt coating was performed using a Sanyu Denshi SC-701C-MC quick cool coater. Light scattering measurements were performed with a Photal Otsuka Electronics ELS-8000 electrophoretic light scattering spectrophotometer equipped with a system controller, an ELS controller, and an He-Ne laser operating at $\lambda=632.8 \mathrm{~nm}$.

2.2. Materials. POA was purchased from Daikin Chemical Co. Ltd. and was deinhibited by passage through an alumina column. tert-Butyl acrylate (TBA) was purified by distillation under reduced pressure over calcium hydride. 2(Dimethylamino)ethyl acrylate (DAA) was distilled under reduced pressure over calcium hydride. Hexafluorobenzene to be used as a solvent for ${ }^{1} \mathrm{H}$ NMR and light scattering measurements was also distilled over calcium hydride. Azobisisobutyronitrile (AIBN) was recrystallized from methanol. Extrapure perfluoroazelaic acid (PA), perfluorosuccinic acid (Psuc), maleic acid (Ma), succinic acid (Suc), glutaric acid (Glu), and azelaic acid (Az) were used without further purification.

2.3. Synthesis of $P(P O A-r-A A)$. POA ( $4.60 \mathrm{~g}, 8.88 \mathrm{mmol})$, TBA (481 mg, $3.75 \mathrm{mmol}$ ), and AIBN (21 mg, $0.128 \mathrm{mmol}$ ) were placed in an ampule. After the contents were degassed, the ampule was sealed in vacuo. The polymerization was carried out at $50^{\circ} \mathrm{C}$ for $2 \mathrm{~h}$ and was terminated by cooling with liquid nitrogen. The reaction mixture was dissolved in $40 \mathrm{~mL}$ of hexafluorobenzene and was poured into $1 \mathrm{~L}$ 
TABLE 4: Contact angles (CAs) on the surface coated with the nanospheres.

\begin{tabular}{lccccccrr}
\hline Acid & Paz $^{\mathrm{a}}$ & $\mathrm{Glu}^{\mathrm{a}}$ & $\mathrm{PSuc}^{\mathrm{a}}$ & $\mathrm{Ma}^{\mathrm{b}}$ & Suc $^{\mathrm{b}}$ & $\mathrm{Az}^{\mathrm{b}}$ & None $^{\mathrm{c}}$ & None $^{\mathrm{d}}$ \\
\hline CA $\left(^{\circ}\right)$ & 165.3 & 171.5 & 170.0 & 165.5 & 164.7 & 171.0 & 161.5 & 96.5 \\
\hline
\end{tabular}

${ }^{\mathrm{a}}$ Acid/DAA $=0.5 .{ }^{\mathrm{b}}$ Acid/DAA $=1.0 .{ }^{\mathrm{c}}$ Treated in $\mathrm{scCO}_{2} .{ }^{\mathrm{d}}$ The cast film prepared from a solution in hexafluorobenzene under atmosphere.
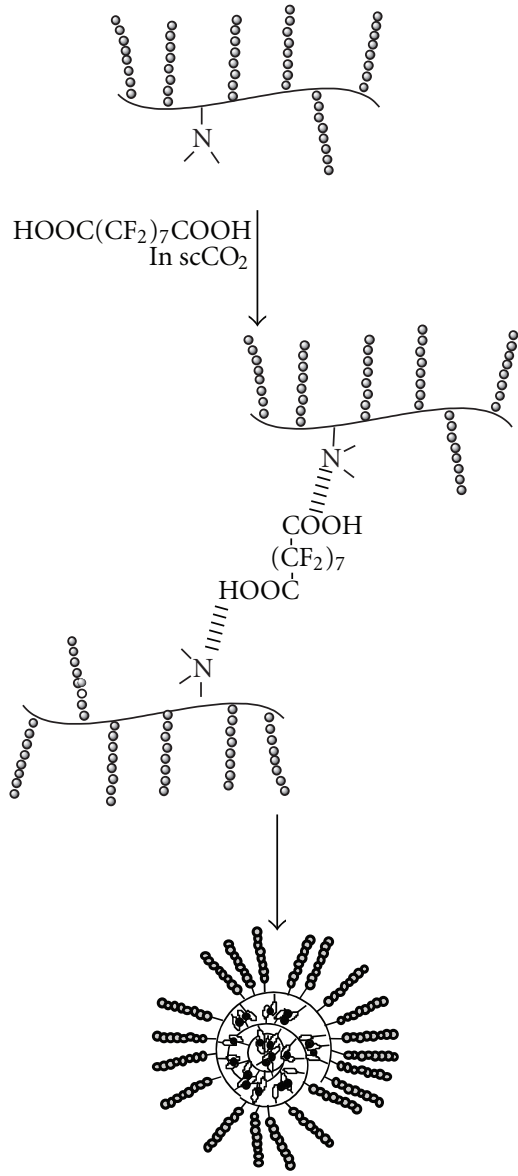

\$0000000 Perfluoroalkyl chain

Scheme 6: A schematic of the formation of the nanospheres.

of methanol to precipitate a polymer. The polymer was collected and was dried in vacuo for several hours to obtain $\mathrm{P}$ (POA- $r$-TBA) (4.44 g). The P(POA- $r$-TBA) (2.00 g) was dissolved in HFIP $(60 \mathrm{~mL})$. Concentrated hydrochloric acid $(2 \mathrm{~mL})$ was added to the copolymer solution at room temperature, and the solution was refluxed for $3 \mathrm{~h}$. After the solution was cooled to room temperature, it was concentrated to one-third of its original volume with an evaporator. The residual solution was poured into hexane $(1 \mathrm{~L})$ to precipitate a polymer. The polymer was purified by reprecipitation from hexafluorobenzene $(5 \mathrm{~mL})$ into hexane $(500 \mathrm{~mL})$. The resulting polymer was dried in vacuo for $5 \mathrm{~h}$ to obtain $\mathrm{P}(\mathrm{POA}-r-\mathrm{AA})(1.76 \mathrm{~g})$.

2.4. Synthesis of $P(P O A-r-D A A)$. POA $(1.64 \mathrm{~g}, 3.16 \mathrm{mmol})$, DAA (0.198 g, $1.38 \mathrm{mmol})$, and AIBN (7.4 mg, $0.0451 \mathrm{mmol})$

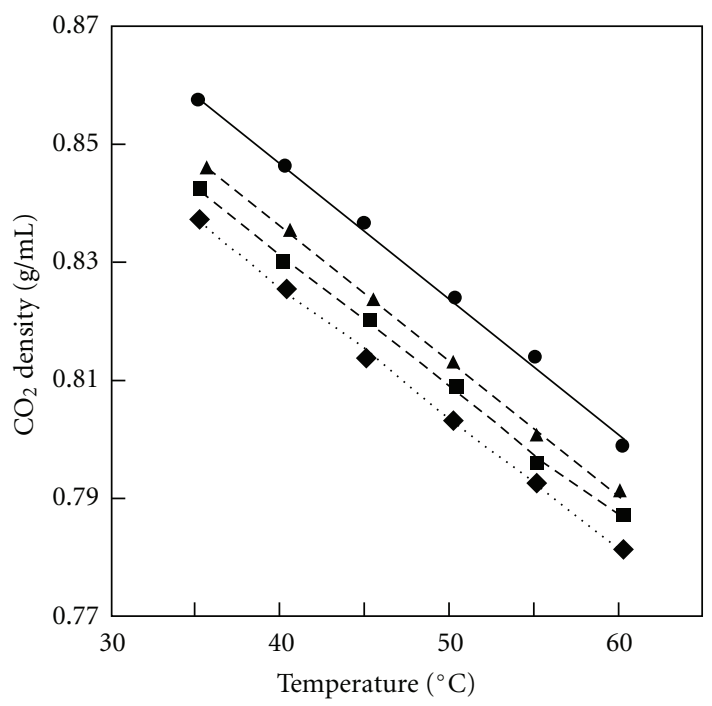

FIGURE 1: Plots of the experimental cloud points of the copolymers with POA/AA of $6 / 4(\bullet), 7 / 3(\boldsymbol{\Delta}), 8 / 2(\boldsymbol{\bullet})$, and $9 / 1(\bullet)$ at each temperature versus the $\mathrm{CO}_{2}$ density.

were placed in ampule. After the contents were degassed, the ampule was sealed in vacuo. The polymerization was carried out at $60^{\circ} \mathrm{C}$ for $10 \mathrm{~min}$ and was terminated by cooling with liquid nitrogen. The reaction mixture was dissolved in hexafluorobenzene and poured into hexane to precipitate a polymer. The precipitate was dried in vacuo for several hours to obtain P(POA-r-DAA) (0.994 g).

2.5. Cloud Point Measurement. The cloud-point measurement was performed with a variable volume view cell (Scheme 2). P(POA-r-AA) (30 mg) was placed in the cell, then $\mathrm{CO}_{2}$ liquefied with a cooler was added to it. The cloud point was defined as the point at which the contents of the cell turned opaque, indicating precipitation of the polymer from solution.

2.6. Preparation of Particles in $\mathrm{ScCO}_{2}$. $\mathrm{P}(\mathrm{POA}-r-\mathrm{AA})(\mathrm{POA} /$ $\mathrm{AA}=7 / 3,30 \mathrm{mg}$ ) was placed in the variable volume view cell, then liquid $\mathrm{CO}_{2}$ was added to it. The solution was stirred at $3620 \mathrm{psi}$ and $45.0^{\circ} \mathrm{C}$ for $10 \mathrm{~min}$. The pressure of the homogeneous solution was reduced until the cloud point (3059 psi) was reached by volume expansion. The pressure was further reduced to $2759 \mathrm{psi}$, and the heterogeneous solution was sprayed into a plastic bag made of polyethylene to collect the polymer particles $(29 \mathrm{mg})$.

2.7. SEM Measurement. The polymer particles were put on a carbon adhesive tape and were subjected to SEM measurement after coated with Pt. 

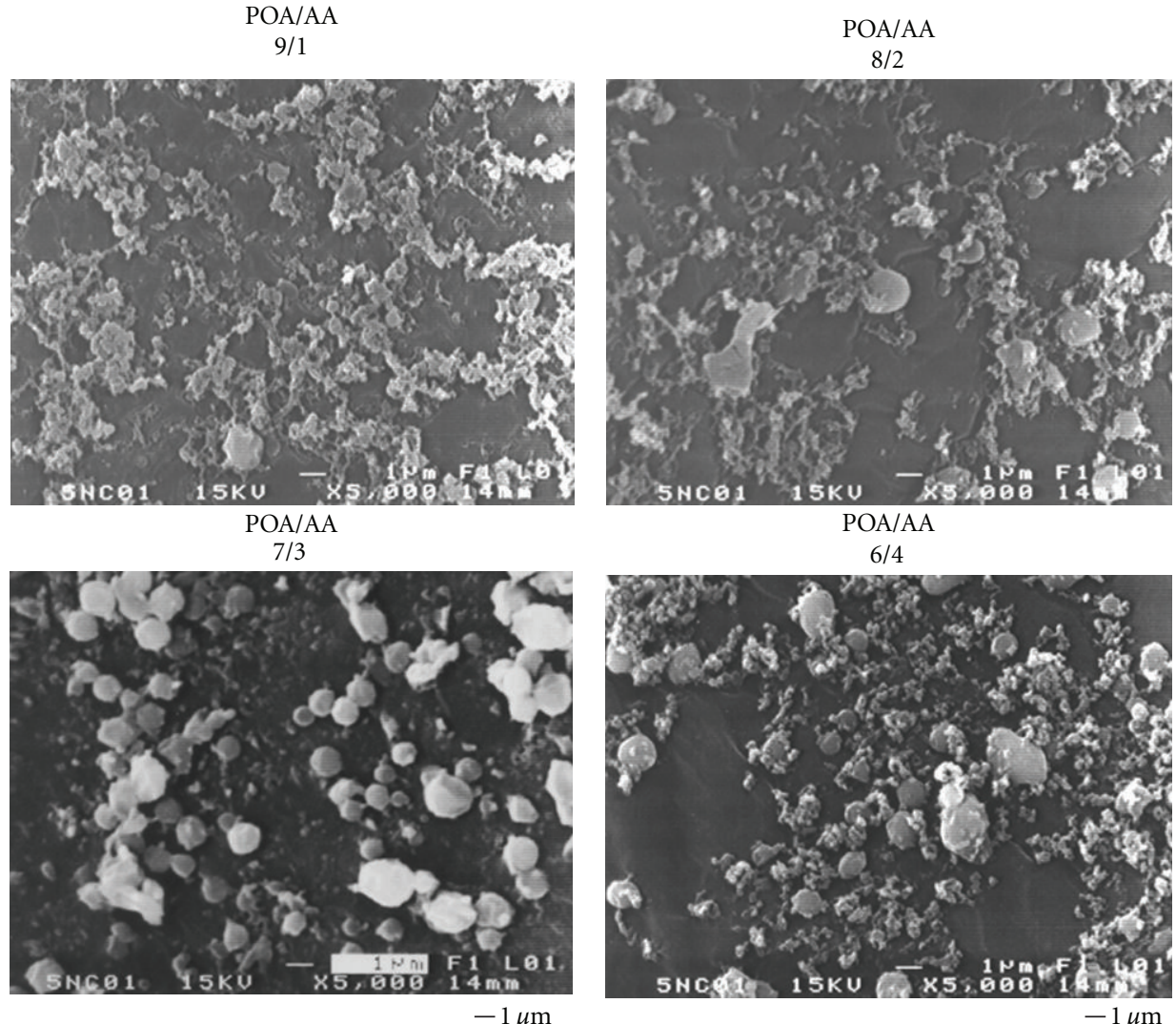

FIGURE 2: SEM images of the polymer particles obtained from the copolymers in $\mathrm{scCO}_{2}$ at $45^{\circ} \mathrm{C}$ and the cloud point pressure -300 psi.

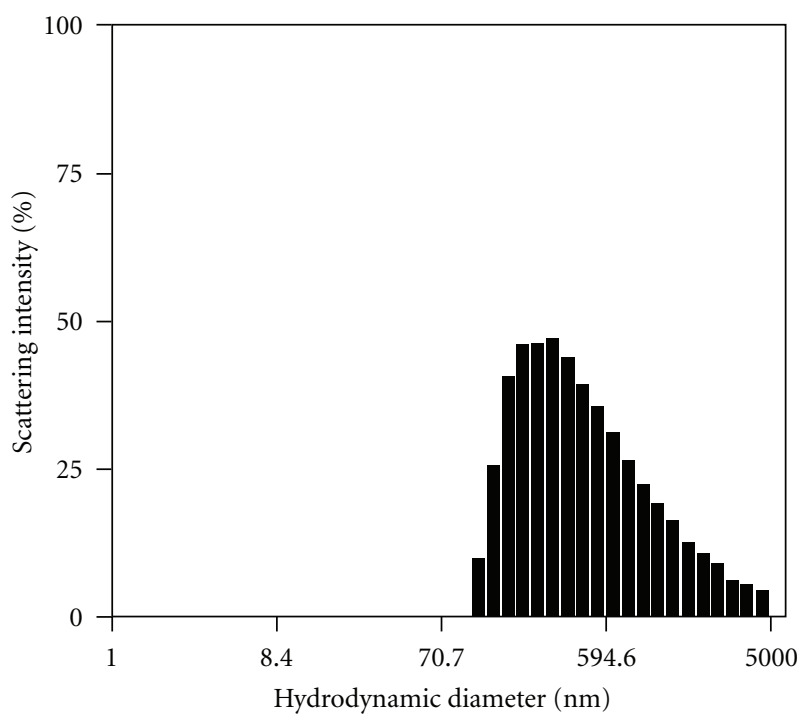

FIGURE 3: Scattering intensity distribution of the hydrodynamic diameter of $\mathrm{P}(\mathrm{POA}-r$ - $\mathrm{AA})$ with a $7 / 3 \mathrm{POA} / \mathrm{AA}$ ratio in hexafluorobenzene at $25^{\circ} \mathrm{C}$ and $\theta=90^{\circ}$. (copolymer) $=8.00 \mathrm{~g} / \mathrm{L}$.

2.8. Contact Angle Measurement. The surfaces completely covered with the nanospheres were prepared on a carbon adhesive tape attached to a slide glass. The contact angles were measured by dropping water $(10 \mu \mathrm{L})$ on the nanosphere-coated surface at ambient temperature. The surface on the cast film of the copolymer was prepared directly on a slide glass from a copolymer solution in hexafluorobenzene.

2.9. Light Scattering Measurements. P(POA-r-AA) (24 mg) was dissolved in $3 \mathrm{~mL}$ of hexafluorobenzene and was subjected to light scattering at $25^{\circ} \mathrm{C}$ at $\theta=90^{\circ}$.

\section{Direct Self-Assembly through Hydrogen Bond}

The $\mathrm{P}(\mathrm{POA}-r-\mathrm{AA})$ random copolymers were obtained by the hydrolysis of $\mathrm{P}(\mathrm{POA}-r$-TBA) prepared by the radical polymerization (Scheme 3$)$. The hydrolysis of $\mathrm{P}(\mathrm{POA}-r$ TBA) was carried out in HFIP using concentrated hydrochloric acid under reflux for $3 \mathrm{~h}$. The characterizations of the $\mathrm{P}(\mathrm{POA}-r$-TBA $)$ and $\mathrm{P}(\mathrm{POA}-r-\mathrm{AA})$ copolymers are listed in Tables 1 and 2 . The molecular weight distributions of $\mathrm{P}$ (POA-r-AA) could not be estimated due to the very broad distribution.

The $\mathrm{P}(\mathrm{POA}-r$-AA) copolymers completely dissolved in $\mathrm{scCO}_{2}$. Figure 1 shows the $\mathrm{CO}_{2}$ density at the cloud points plotted versus temperature. The $\mathrm{CO}_{2}$ density at the cloud points decreased as the temperature increased, indicating that the solubility of the copolymers increased with 


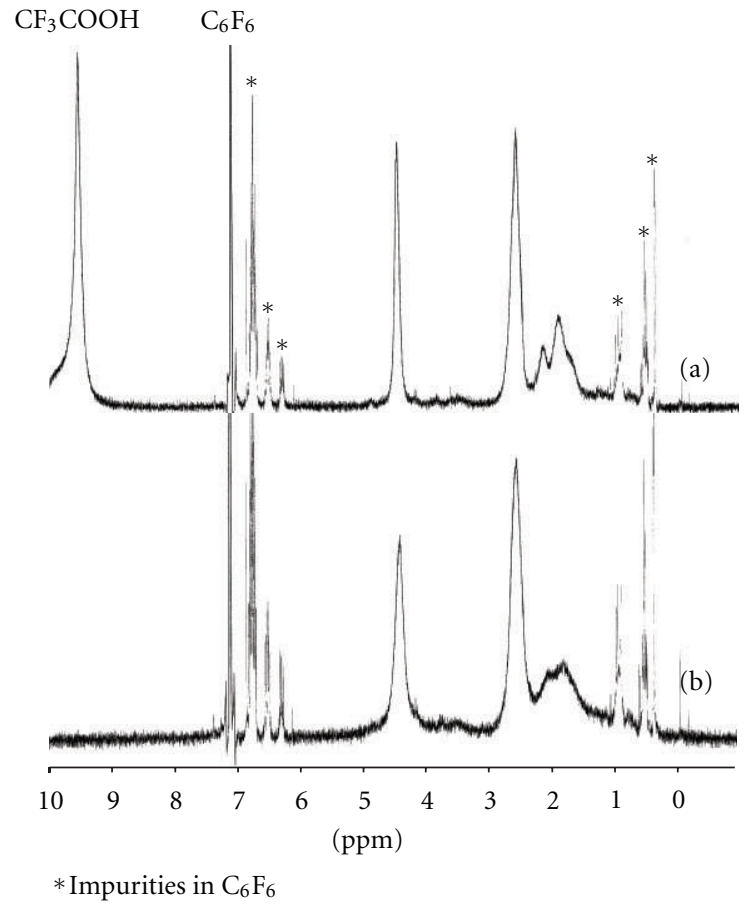

Figure 4: ${ }^{1} \mathrm{H}$ NMR spectra of $\mathrm{P}(\mathrm{POA}-r$-AA) with a $7 / 3$ POA/AA ratio in the presence (a) and absence (b) of $\mathrm{CF}_{3} \mathrm{COOH}$. Solvent: $\mathrm{C}_{6} \mathrm{~F}_{6}$ including $\mathrm{C}_{6} \mathrm{D}_{6}$.

the increasing temperature. And further, the copolymer with a higher AA ratio had a lower solubility, suggesting that the hydrogen bonding based on the AA units prevented the copolymer from dissolving in $\mathrm{scCO}_{2}$.

SEM observations revealed that the $\mathrm{P}(\mathrm{POA}-r-\mathrm{AA})$ copolymers self-assembled into spherical particles in $\mathrm{scCO}_{2}$. Figure 2 shows the SEM images of the particles obtained from the copolymer solution at $45^{\circ} \mathrm{C}$ in a heterogeneous state at a pressure lower than the cloud point pressure. The images included spherical particles independent of the POA/AA ratio. However, the proportion of the spherical particles was different among the various ratios. The copolymers with the $9 / 1$ and $8 / 2$ ratios contained some spherical particles of several micrometers in diameter and a lot of small particles with nonspecific forms. These copolymers had too low AA content to aggregate into spherical forms. The copolymer with the 6/4 ratio also contained both the spherical particles and the small particles. However, the small particles also had a spherical shape with several hundreds of nanometer diameters. It is likely that the intramolecular aggregation is preferable for the 6/4 sample due to large contribution of the hydrogen bonding based on the higher AA content. The copolymer with the $7 / 3$ ratio produced the largest amount of spherical particles among the copolymers. Based on the SEM image of the $7 / 3$ sample, the size of the spherical particles was estimated to be $820 \mathrm{~nm}$ on average, and the size distribution was 1.20 [27]. These SEM images are for the polymer particles obtained by spraying the heterogeneous solutions into the atmosphere, based on the assumption that the shapes of the particles formed in $\mathrm{scCO}_{2}$ are maintained in

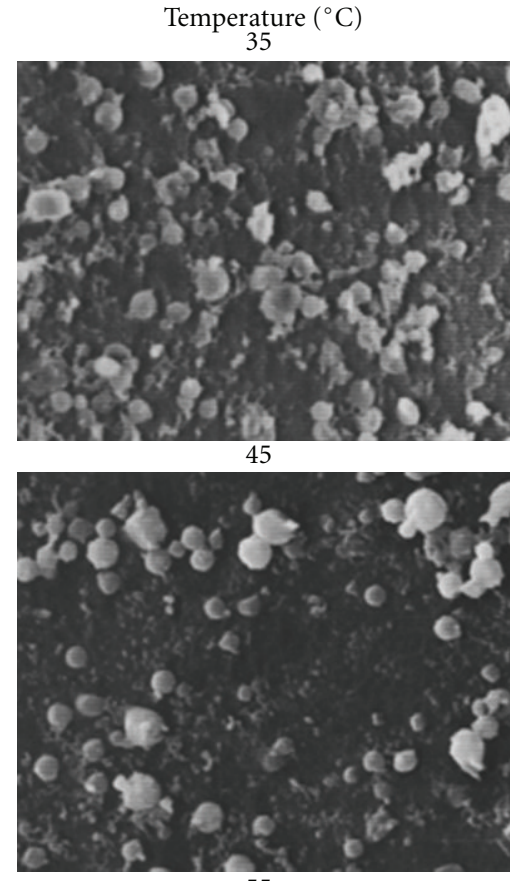

55

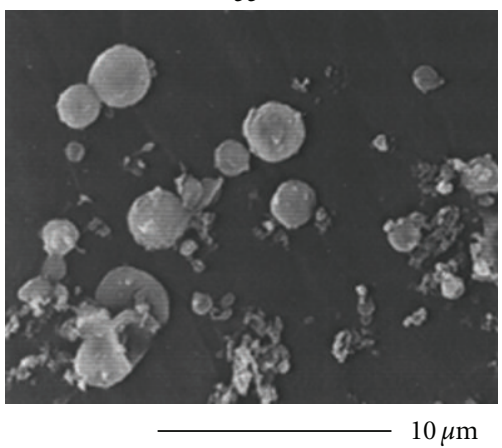

Figure 5: SEM images of the polymer particles obtained at 35, 45, and $55^{\circ} \mathrm{C}$ at the cloud point pressure -300 psi.

this atmosphere at ambient temperature by rapidly releasing the $\mathrm{CO}_{2}$ pressure.

In order to confirm the formation of the particles in solution, the light scattering measurements of the copolymer were performed in hexafluorobenzene. Hexafluorobenzene is similar to $\mathrm{scCO}_{2}$ in having low polarity and the ability to dissolve fluoropolymers. Figure 3 shows the scattering intensity distribution of the hydrodynamic diameter of the particles formed by the copolymer with the $7 / 3$ ratio in hexafluorobenzene. The intensity distribution was obtained by a Marquadt analysis of the dynamic light scattering results. The hydrodynamic diameter of the particles was estimated to be $600 \mathrm{~nm}$ based on the Marquadt analysis. Compared with the particle size based on the SEM image, the copolymer formed smaller particles in hexafluorobenzene. This can be accounted for by the fact that the AA units more tightly formed the particle cores in hexafluorobenzene than in $\mathrm{scCO}_{2}$ because of the lower affinity of hexafluorobenzene to the AA units and also that the particles swelled when rapidly sprayed into the atmosphere. 


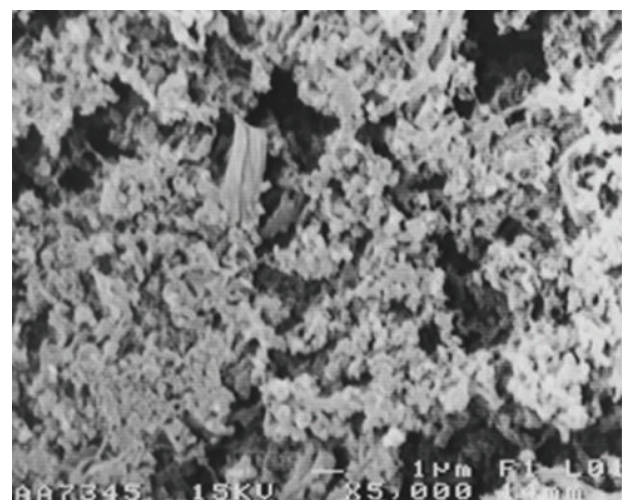

(a)

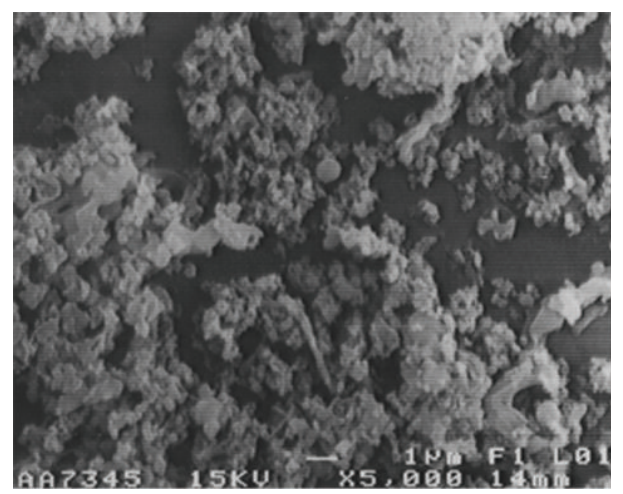

(b)

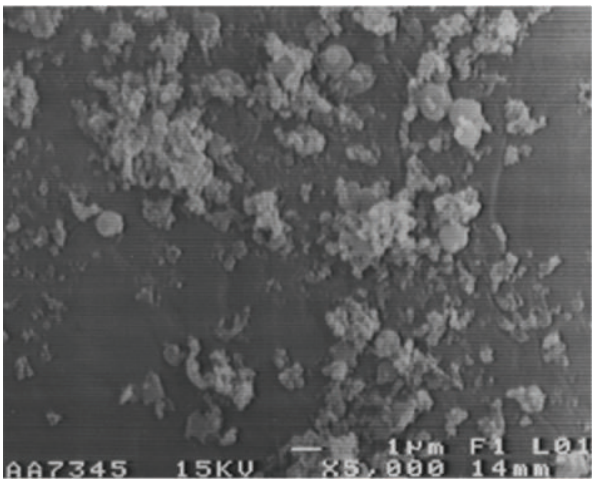

(c)

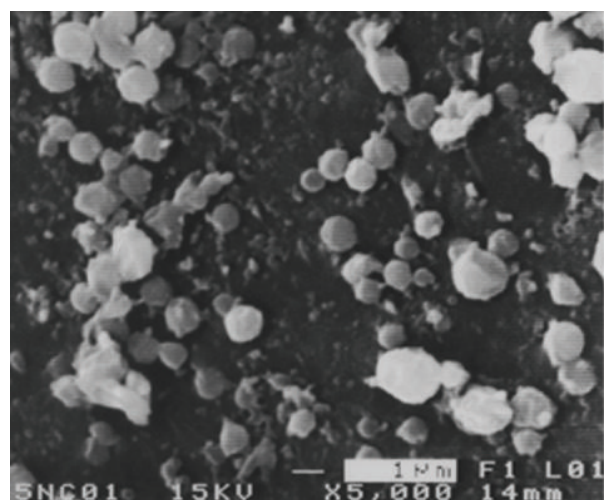

(d)

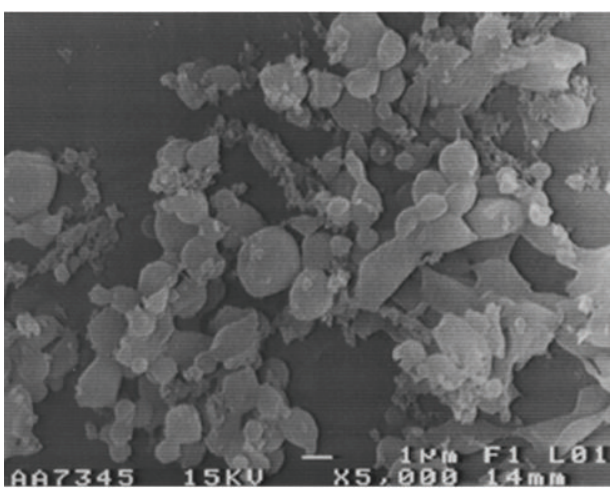

(e)

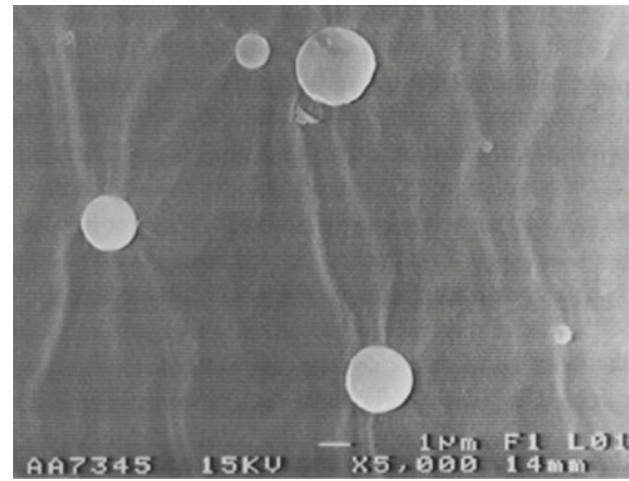

(f)

$-1 \mu \mathrm{m}$

FIGURE 6: SEM images of the polymer particles obtained at the cloud point pressure +200 (a), \pm 0 (b), -100 (c), -300 (d), -900 (e), and -1500 psi (f).

The ${ }^{1} \mathrm{H}$ NMR analysis confirmed that the particles consisted of the POA unit shells and the AA unit cores. The ${ }^{1} \mathrm{H}$ NMR spectra of the copolymer in the presence and absence of trifluoroacetic acid are shown in Figures 4(a) and 4(b). The copolymer showed no aggregation in the presence of trifluoroacetic acid. The signals based on the methyne and methylene of the main chain were broadened in the absence of trifluoroacetic acid, as compared to those in its presence. This broadening of the signals indicates that the insoluble AA units and main chains were shielded from the magnetic field. Consequently, it is expected that the copolymers formed random copolymer micelles consisting of the shells of the $\mathrm{CO}_{2}$-philic perfluorooctyl groups and the cores of the $\mathrm{CO}_{2}$-phobic $\mathrm{AA}$ units and main chains when the copolymers were placed in $\mathrm{scCO}_{2}$ as well as in hexafluorobenzene (Scheme 4).

The shapes of the polymer particles were dependent on temperature based on the formation by hydrogen bonding. Figure 5 shows the SEM images of the polymer particles obtained at three different temperatures in the heterogeneous state. The particles were not completely spherical at $35^{\circ} \mathrm{C}$. The copolymer could not completely take a spherical shape because of the low mobility of the copolymer at this low temperature. On the other hand, the copolymer produced large 

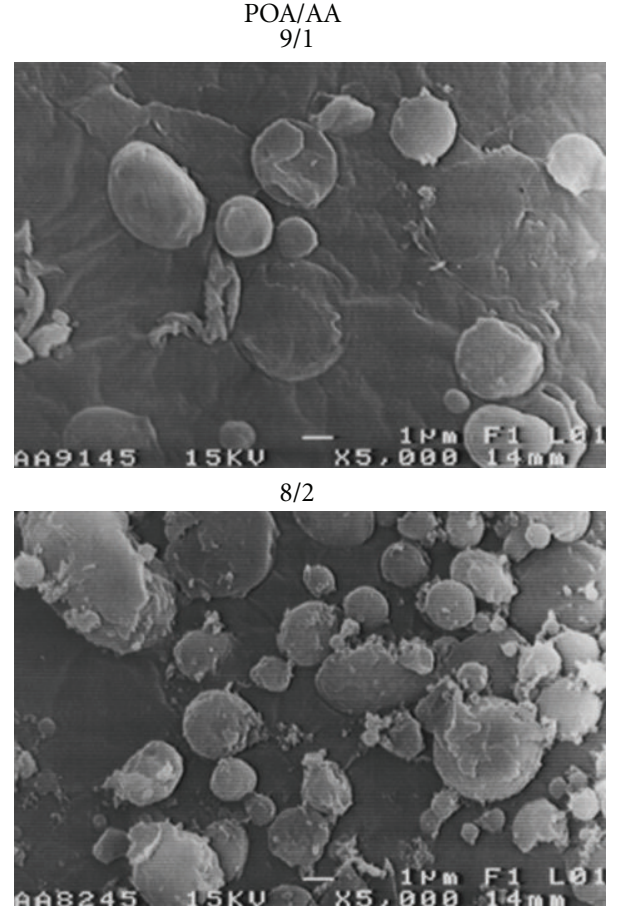

$-1 \mu \mathrm{m}$

FIGURE 7: SEM images of the polymer particles obtained from the copolymers with $9 / 1$ and $8 / 2 \mathrm{POA} / \mathrm{AA}$ ratios at $45^{\circ} \mathrm{C}$ and the cloud point pressure -1500 psi.

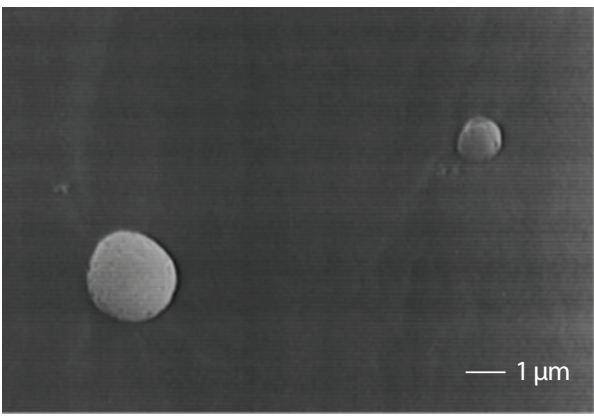

(a)

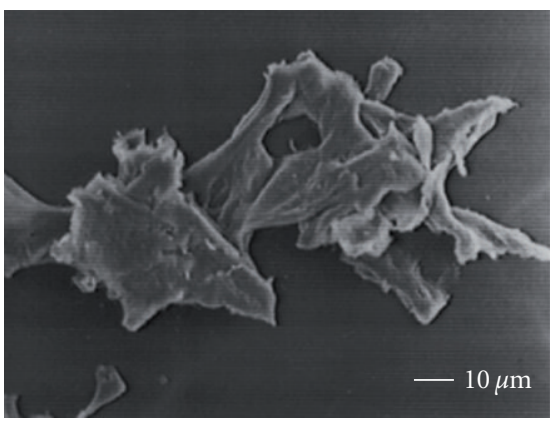

(b)

FIGURE 8: SEM images of the polymer particles obtained from the copolymer with a $6 / 4 \mathrm{POA} / \mathrm{AA}$ ratio at $45^{\circ} \mathrm{C}$ and the cloud point pressure -1500 psi.

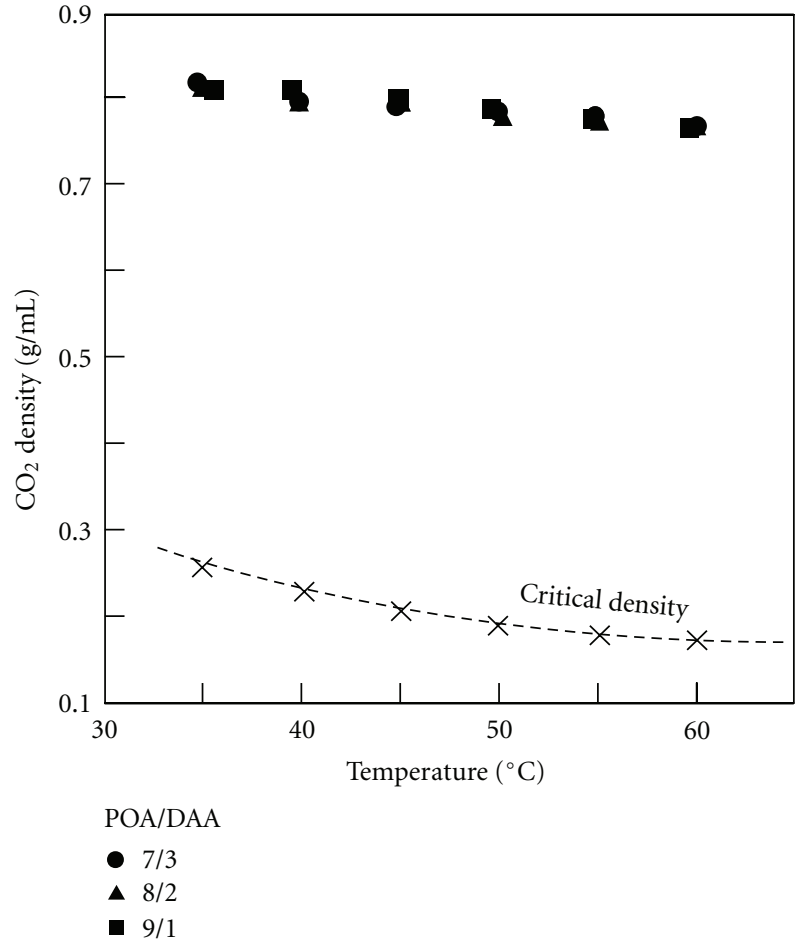

FIgURE 9: Plots of the experimental cloud points of the copolymers at each temperature versus the $\mathrm{CO}_{2}$ density.

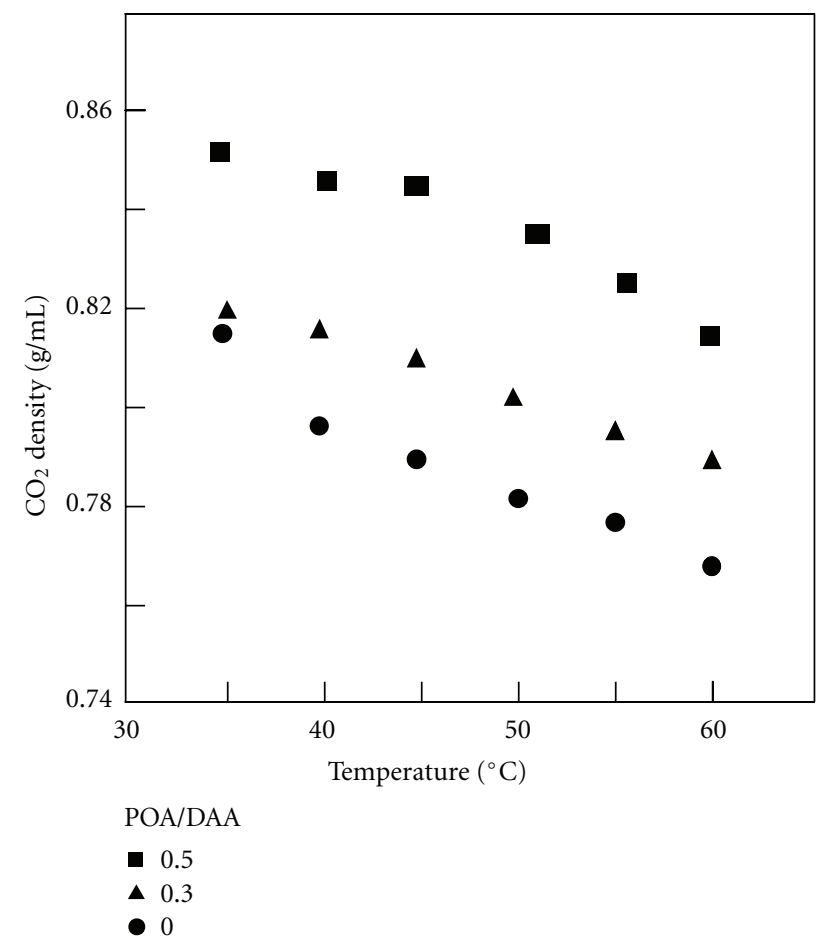

Figure 10: Plots of the cloud points of the copolymer with $7 / 3$ of POA/DAA in the presence of PA at 0.3 and 0.5 of PA/DAA. 


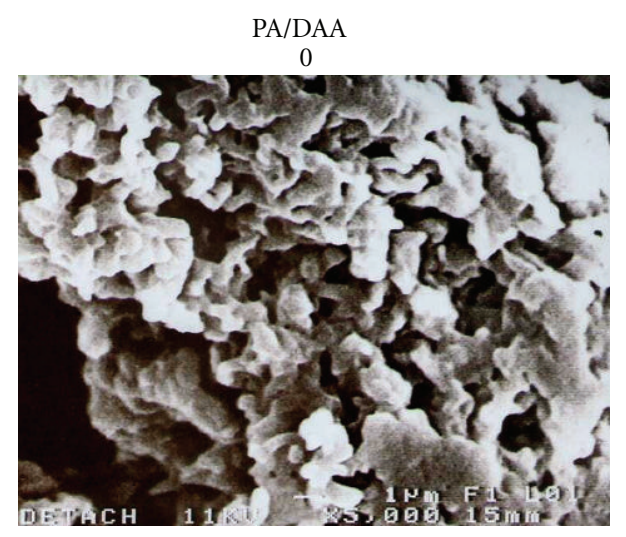

0.3

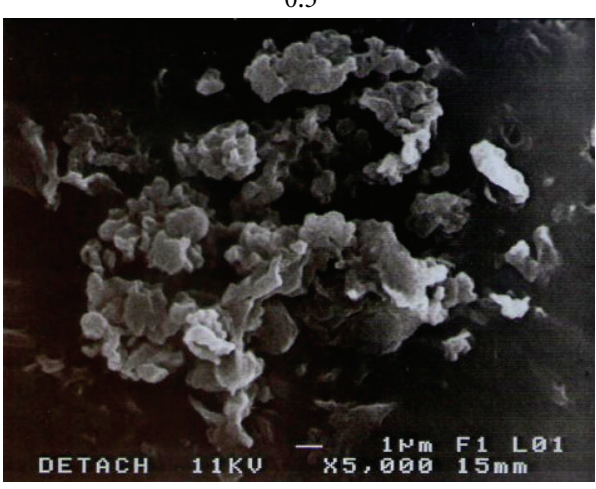

0.5

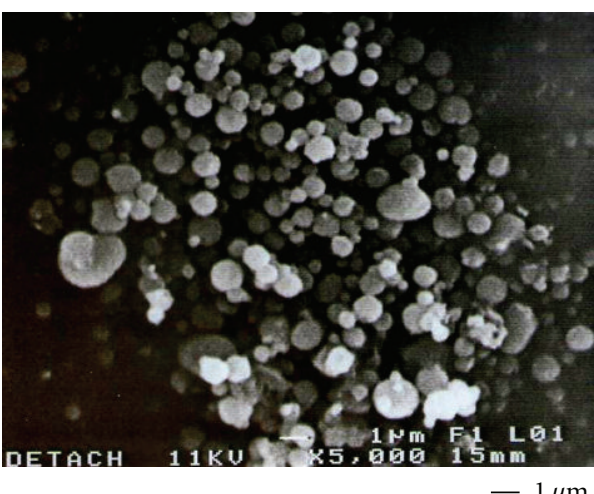

$-1 \mu \mathrm{m}$

FIGURE 11: SEM images of the copolymer in the absence and presence of $\mathrm{PA}$. POA/DAA $=7 / 3$, heterogeneous state.

spherical particles of several micrometers at $55^{\circ} \mathrm{C}$, along with small particles with hundreds of nanometer diameters. It was considered that an increase in the mobility of the copolymer at the high temperature promoted both the intermolecular aggregation and the intramolecular association.

The self-assembly of the copolymers into spherical particles was controlled by the $\mathrm{CO}_{2}$ pressure. Figure 6 shows the SEM images of the polymer particles produced under the different pressures. The particles produced at a pressure higher than the cloud point pressure had nonspecific forms.
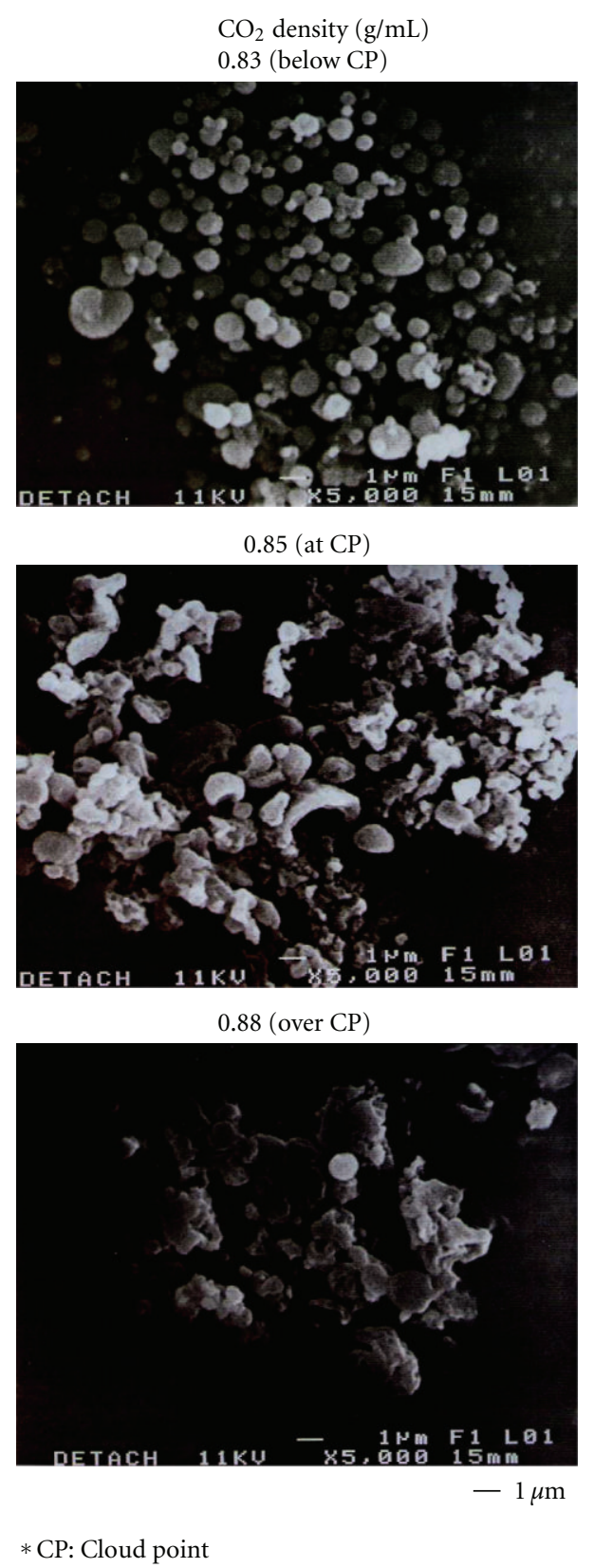

FIGURE 12: SEM images of polymer particles obtained from the heterogeneous state below the cloud point, the state at the exact cloud point, and the homogeneous state over it. $\mathrm{POA} / \mathrm{DAA}=7 / 3$, $\mathrm{PA} / \mathrm{DAA}=0.5$.

Spherical particles were hardly observed in the image. The particles prepared at the cloud point pressure included a small amount of spherical parts, however, most of the particles were still nonspecific. When the pressure was reduced to $100 \mathrm{psi}$ lower than the cloud point pressure, the copolymer somewhat aggregated into spherical particles. At a pressure 300 psi lower than the cloud point, most of the particles had spherical shapes. However, it was observed that the spherical particles partly combined at the cloud point pressure minus 900 psi. Completely spherical and larger-sized particles were 


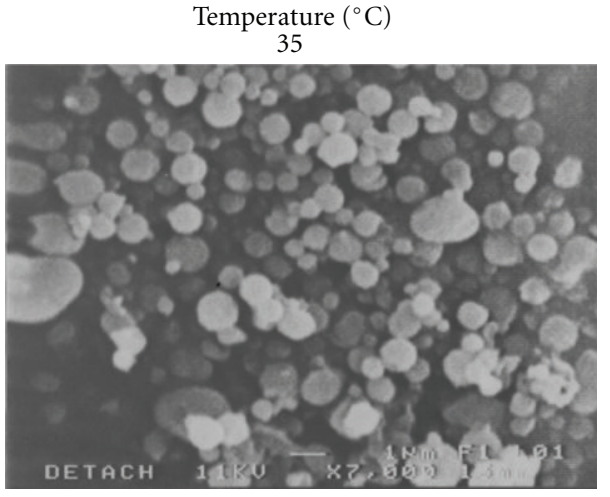

45

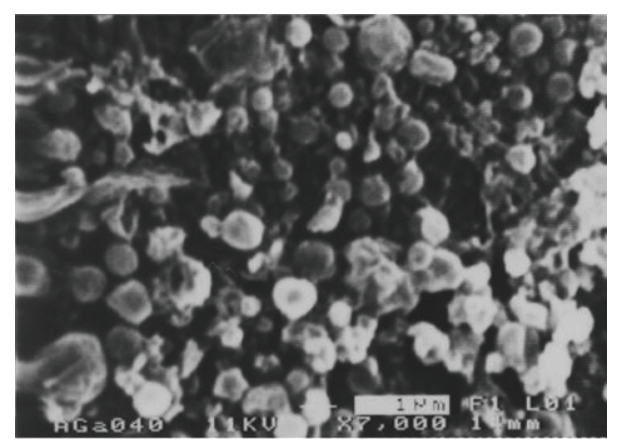

60

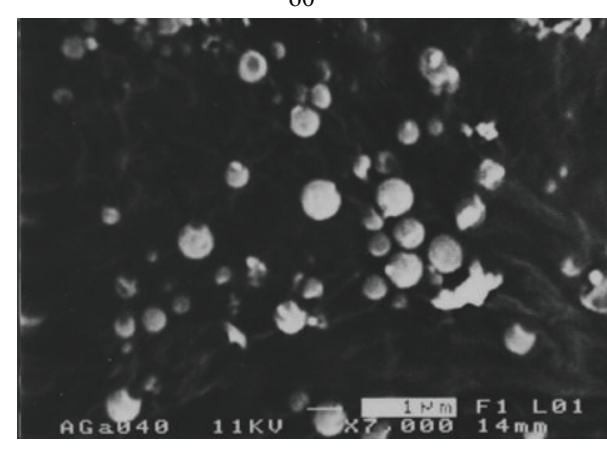

$-1 \mu \mathrm{m}$

FIGURE 13: SEM images of the polymer particles obtained at 35, 45, and $60^{\circ} \mathrm{C} . \mathrm{PA} / \mathrm{DAA}=0.5$.

produced at the cloud point minus 1500 psi. It was found that more stable spherical particles were produced at the lower pressure and that the self-assembly of the copolymer was controlled through varying the solvent quality manipulated by the $\mathrm{CO}_{2}$ pressure.

The copolymers with the $9 / 1$ and $8 / 2$ ratios were found to produce nearly spherical particles at the pressure $1500 \mathrm{psi}$ lower than the cloud point pressure, although a few spherical particles were obtained at the cloud point pressure minus 300 psi (Figure 7 ). The hydrogen bonding interaction among the AA units increased with the decreasing pressure, thus the self-assembly of the copolymers into spherical particles was promoted. At the pressure 1500 psi lower than the cloud point, the copolymer with the 6/4 ratio formed not only spherical particles (Figure 8(a)), but also a small amount of nonspecific aggregates of dozens or hundreds micrometers
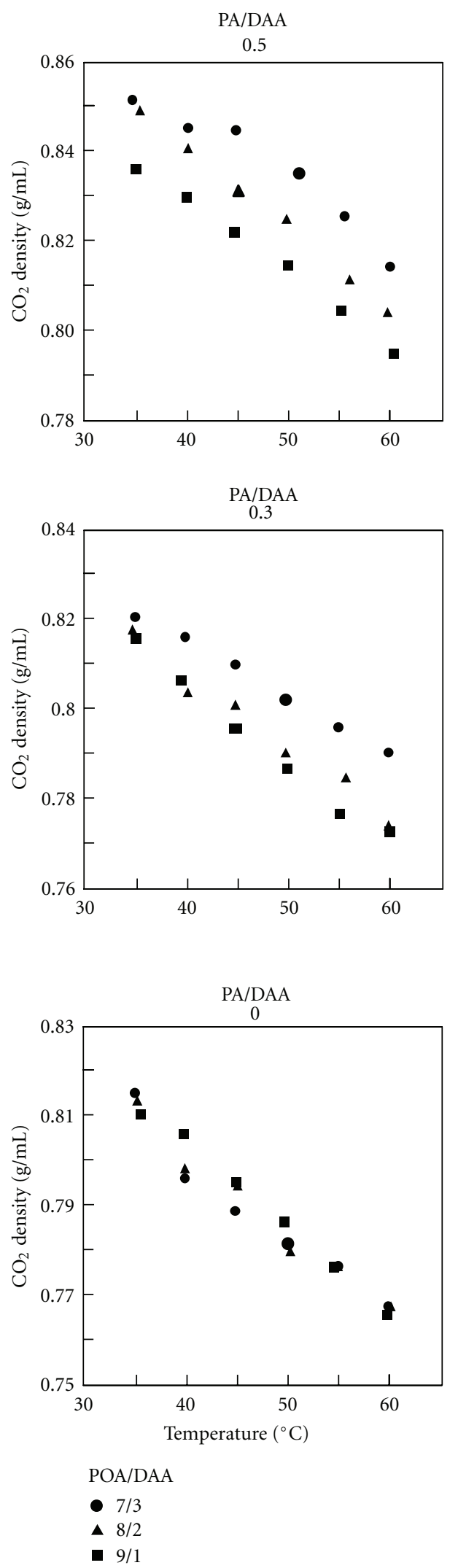

FIGURE 14: Plots of the cloud points of the copolymers with POA/DAA of $7 / 3,8 / 2$, and $9 / 1$ in the absence and presence of PA at 0.3 and 0.5 of PA/DAA. 

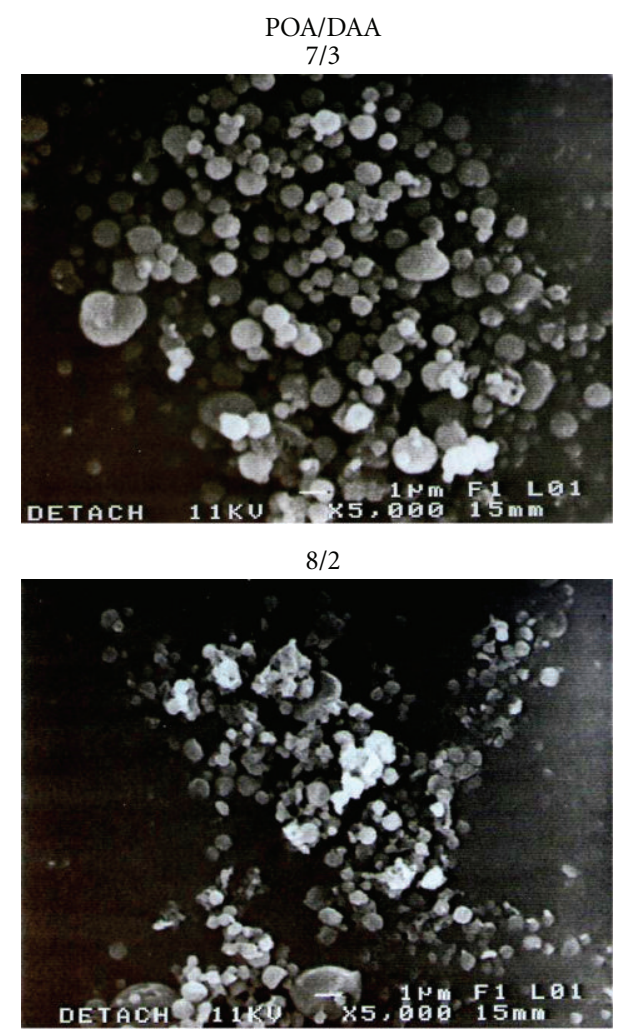

$9 / 1$

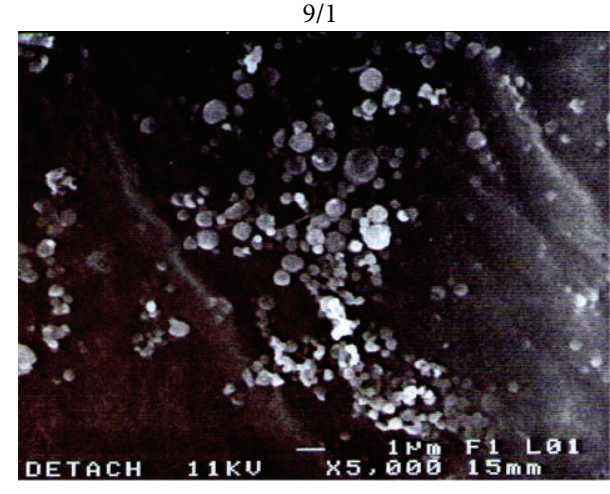

$-1 \mu \mathrm{m}$

FIGURE 15: SEM images of the nanospheres obtained from the copolymers with POA/DAA of $7 / 3,8 / 2$, and $9 / 1$. PA/DAA $=0.5$, heterogeneous state.

(Figure 8(b)). Too strong hydrogen bonding at a very low pressure should have caused a partial second aggregation of the spherical particles into large nonspecific particles. It was deduced that the formation of spherical particles could be optimized by the manipulation of the $\mathrm{CO}_{2}$ pressure for the different compositions of the copolymers.

\section{Indirect Self-Assembly through Hydrogen Bond}

It is possible to induce self-assembly for a copolymer that shows no self-assembly by itself through hydrogen bond

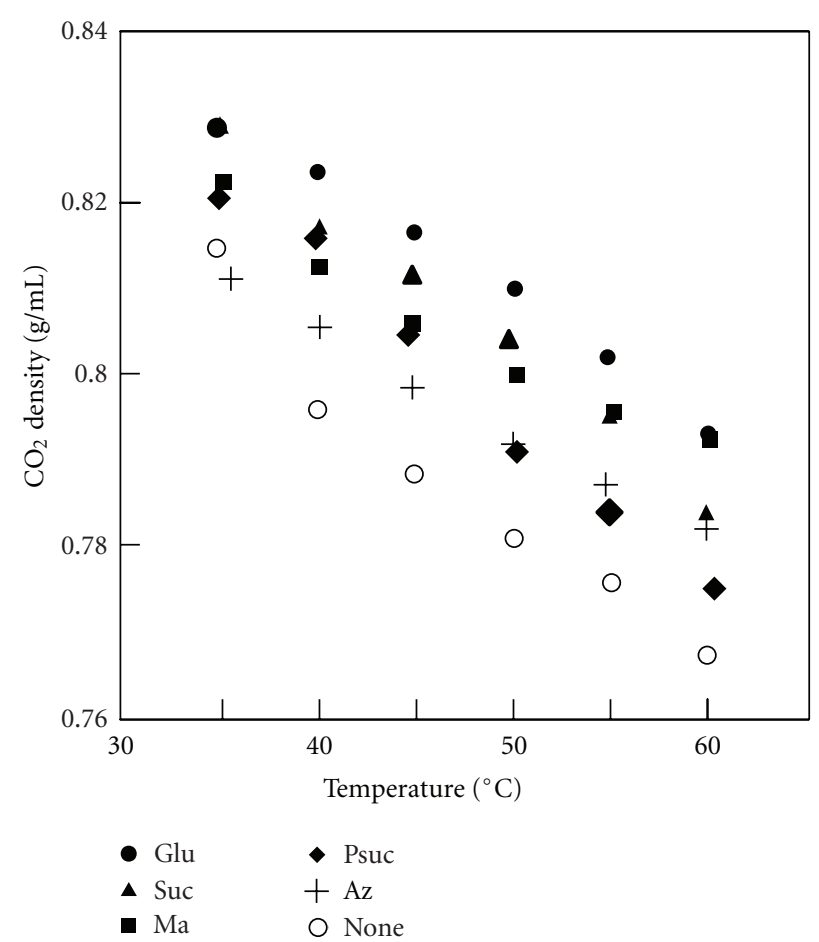

FIGURE 16: Plots of the experimental cloud points of the P(POA- $r$ DAA) copolymer in the presence of the dicarboxylic acids at each temperature. The acid/DAA $=0.5$.

interaction with additives. $\mathrm{P}(\mathrm{POA}-r$-DAA) random copolymers dissolve in $\mathrm{scCO}_{2}$, however, these copolymers show no self-assembly in it. The characterizations of the P(POA$r$-DAA) copolymers prepared by radical copolymerization are listed in Table 3 (Scheme 5). Figure 9 shows the plots of the cloud points versus the $\mathrm{CO}_{2}$ density. There was a slight difference in the cloud point among the POA/DAA ratios of the copolymers. It was found that the solubility of the copolymers in $\mathrm{scCO}_{2}$ decreased in the presence of perfluoroazelaic acid (PA). Figure 10 shows the cloud points of the copolymer with $7 / 3$ of POA/DAA in the absence and presence of $\mathrm{PA}$ at 0.3 and 0.5 as a molar ratio of $\mathrm{PA}$ to the DAA unit. As a result of increasing the amount of PA, the cloud points were shifted to a higher side of the $\mathrm{CO}_{2}$ density. The copolymer became less soluble in the presence of PA. The decrease in the solubility should be caused by hydrogen bond cross-linking between the amino groups in the copolymer via the carboxylic groups of PA.

SEM observation demonstrated that the copolymer formed different shapes in the absence and presence of PA in $\mathrm{scCO}_{2}$. Figure 11 shows the SEM images of the copolymer with and without PA. The images were obtained for the polymer particles produced in the heterogeneous state below the cloud points. The copolymer took unspecific forms in the absence of PA. There was a slight difference in the shape at 0.3 as the PA/DAA ratio. On the other hand, the copolymer had spherical forms at the 0.5 ratio. The size of the particles was ca. $700 \mathrm{~nm}$. At 0.5 of PA/DAA, all the amino groups interact with the carboxylic group of $\mathrm{PA}$, so that no free amino 

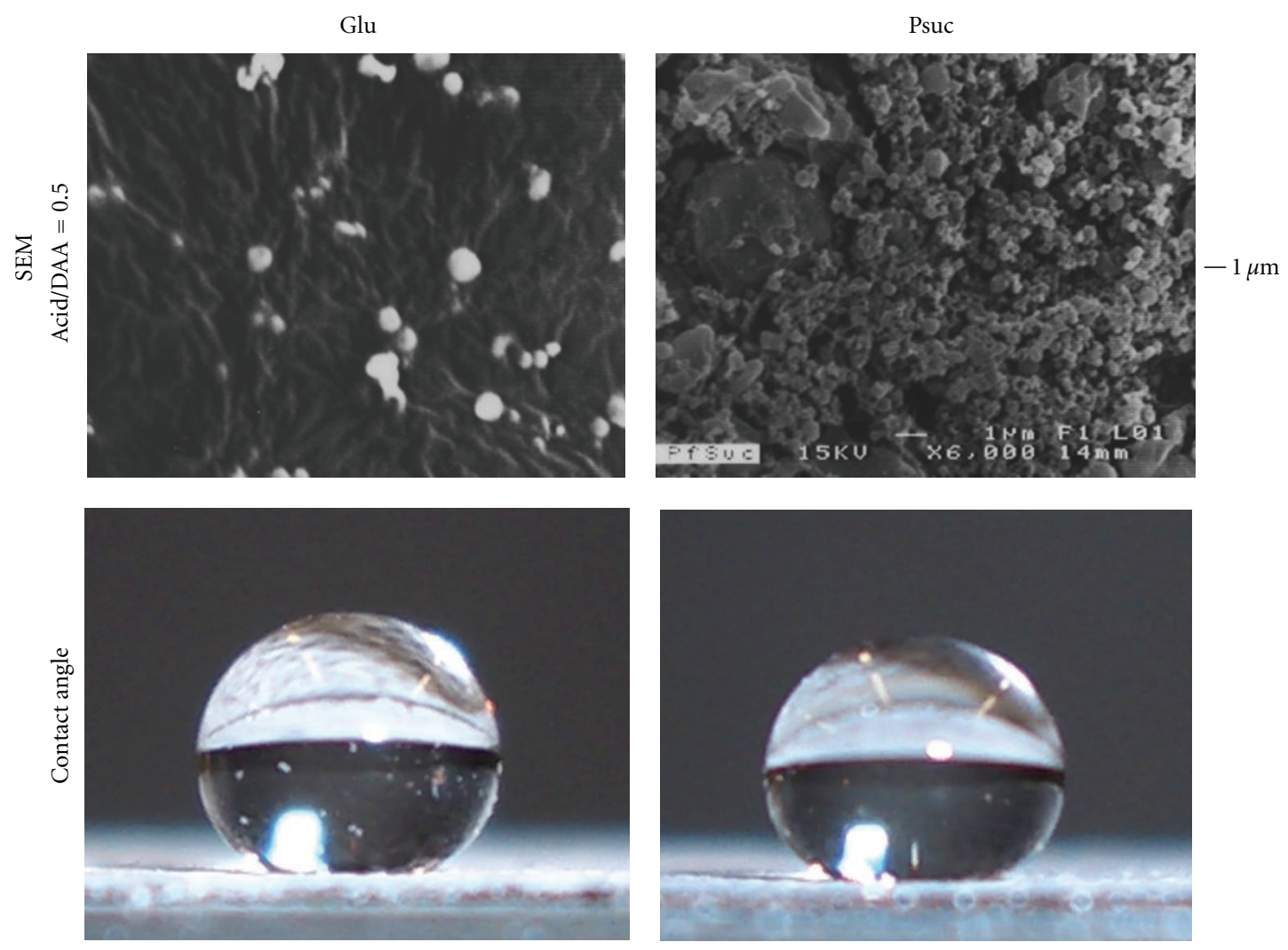

FIGURE 17: SEM images of the particles produced by the copolymer in the presence of Glu and Psuc, and photographs of water droplets placed on the surface coated with the particles.

groups are expected to exist in the copolymer. Therefore, the nanospheres should be formed by cross-linking between the amino groups in the copolymer through the electrostatic interaction with PA (Scheme 6).

We explored the stability of the nanospheres versus pressure. Figure 12 shows the SEM images of polymer particles obtained from three different states: the heterogeneous state below the cloud point, the state at the exact cloud point, and the homogeneous state over it. The pressure at the heterogeneous state was 300 psi lower than the cloud point pressure, while that at the homogeneous state was 500 psi higher. The particles included PA at the 0.5 ratio. The spherical particles formed in the heterogeneous state partly changed to unspecific forms as a result of increasing the pressure to the cloud point pressure. The nanospheres completely changed to unspecific forms over the cloud point. These changes were based on the cross-linking by the weak electrostatic interaction and on an increase in the solubility of the nanospheres into $\mathrm{scCO}_{2}$ as a result of increasing the density of $\mathrm{CO}_{2}$. Consequently, the shape of the polymer particles was dependent not only on the acid concentration but also on the pressure of $\mathrm{CO}_{2}$.

The spherical shapes of the polymer particles were independent of the temperature. Figures 13 shows the SEM images of the polymer particles obtained at 35,45 , and $60^{\circ} \mathrm{C}$ at 0.5 of PA/DAA. The particles were prepared in the heterogeneous states at which the pressures were $300 \mathrm{psi}$ lower than the cloud point pressure at each temperature.
The polymer particles maintained their spherical shapes at 45 and $60^{\circ} \mathrm{C}$. In addition, the copolymer with PA took more completely spherical shape with an increase in the temperature. It may be accounted for by the fact that the perfluoroalkyl chains extend much more at higher temperature, resulting in that the copolymer more easily form spherical particles at the higher temperature.

The POA/DAA ratio in the copolymer affected the cloud point and size of the nanospheres. Figure 14 shows the cloud points of three different copolymers with POA/DAA of $7 / 3,8 / 2$, and $9 / 1$ in the presence of $\mathrm{PA}$ at 0.3 and 0.5 of PA/DAA. Whereas there was a negligible difference in the cloud point among the copolymers in the absence of PA, the copolymers made a marked difference in the presence of it. This difference was much greater as the amount of PA increased. The copolymer having a lower DAA content showed lower cloud point in the presence of PA. The SEM observation revealed that the copolymer with a lower DAA content formed smaller nanospheres. Figure 15 shows the SEM images of the nanospheres obtained from the copolymers with PA at the 0.5 ratio. The size of the nanospheres decreased as the DAA content decreased. The copolymer with the $8 / 2$ ratio formed the nanospheres with ca. $600 \mathrm{~nm}$ as the particle size, while the $9 / 1$ copolymer produced those with $400 \mathrm{~nm}$. The decrease in the size of the nanospheres with the decrease in the DAA content may be account for by the fact that the copolymer with lower DAA content forms a lower degree of cross-linking 

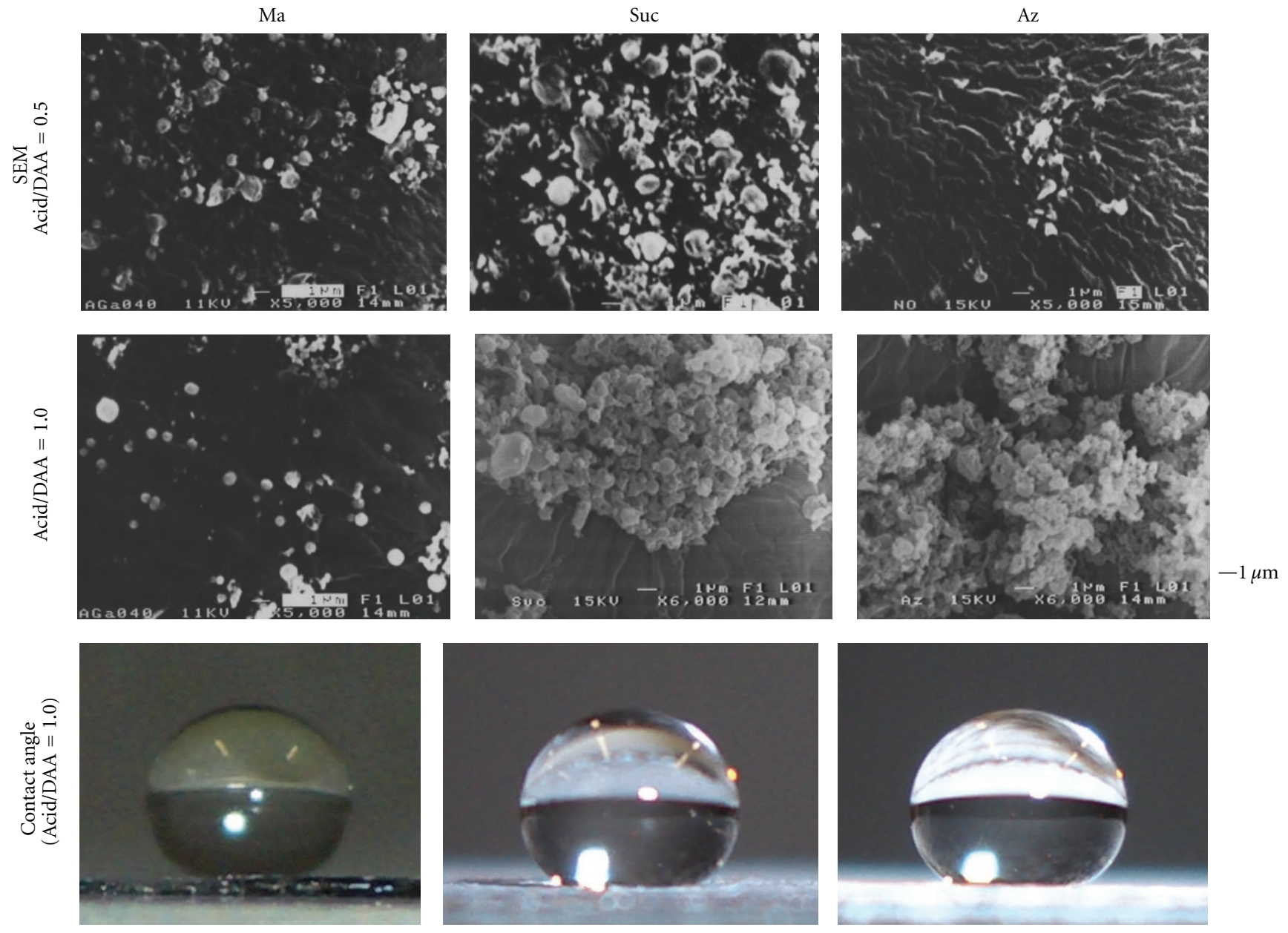

FIGURE 18: SEM images of the particles produced by the copolymer in the presence of Ma, Suc, and Az, and photographs of water droplets placed on the surface coated with the particles.

with the dicarboxylic acid, providing smaller aggregation numbers of the nanospheres. The nanospheres obtained from the copolymers with $8 / 2$ and $9 / 1$ of POA/DAA showed the same results about the amount of PA and the pressure of $\mathrm{CO}_{2}$ as those from the copolymers with $7 / 3$. It was deduced that the size of nanospheres was manipulated by the POA/DAA ratio in the copolymer.

The self-assembly of P(POA- $r$-DAA) by other carboxylic acids was also investigated. Figure 16 shows the plots of the experimental cloud points of the copolymer at each temperature for Psuc, Suc, Glu, Az, and Ma. The $\mathrm{CO}_{2}$ density at the cloud points were shifted to a lower density in the order of Glu $>$ Suc $>\mathrm{Ma}>$ Psuc, Az, indicating that the solubility of the particles formed by the copolymer and the acids increased in this order.

SEM observations revealed that the solubility of the particles to $\mathrm{scCO}_{2}$ was dependent on the size and forms of the particles. Figures 17 and 18 show the SEM images of the particles produced by the copolymer in the presence of the respective acids. Glu and Psuc provided spherical particles at 0.5 of the acid/DAA (Figure 17). Psuc produced smaller nanospheres than Glu. On the other hand, Ma, Suc, and
Az provided random forms of the copolymer rather than spherical particles at this ratio (Figure 18). Ma produced nanospheres at 1.0. Suc and Az also produced spherical particles at 1.0, however, there were very smaller particles with a several hundred nanometer size along with the nanospheres. These three acids had a lower ability to make the copolymer aggregate into nanospheres because of the weak acidity and too short or too long chain length. Consequently, there was a tendency that the solubility of the particles decreased as the form of the copolymer became spherical from the random forms. The formation of the smaller particles seems to increase the solubility of the copolymer.

The nanospheres have the shells composed of the perfluoroalkyl chains from the POA units and cores of the DAA units cross-linked through the hydrogen bonding via the acids. Therefore, the surface on the nanospheres is expected to have a high water repellence based on the perfluorinated shell. It was found that the surface coated with the nanospheres had water contact angles greater than $164^{\circ}$ (Table 4). The largest contact angle was obtained for Glu at $171.5^{\circ}$. The nonspecific forms of the particles had a contact angle at $161.5^{\circ}$ (Figure 19). The roughness of the surface 

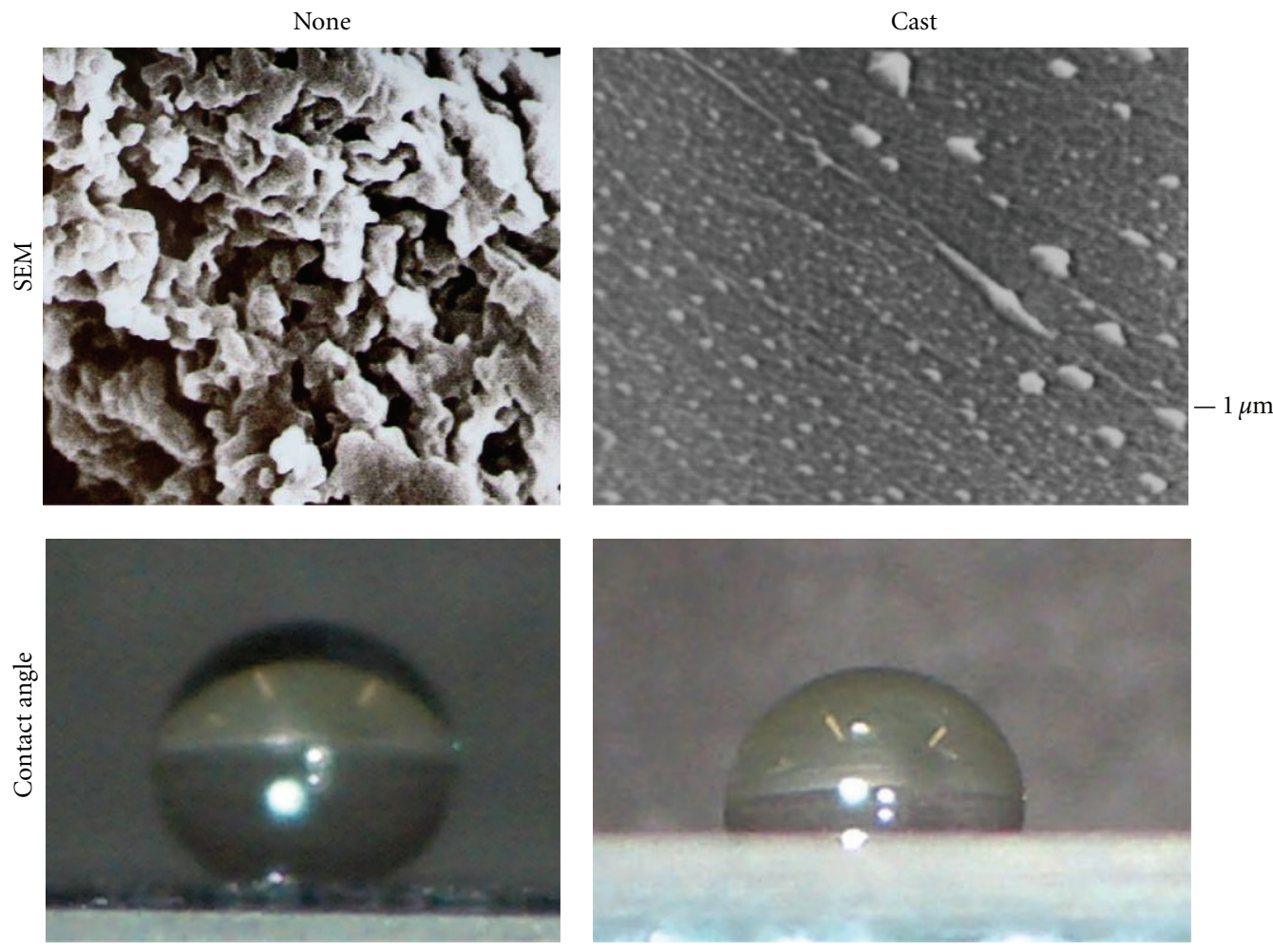

FIGURE 19: SEM images of the random forms produced by the copolymer and of the surface on the cast films. Also shown are photographs of water droplets placed on the surface of the random forms produced by the copolymer and of the surface on the cast films.

due to the nonspecific forms made some contribution to enhancing the hydrophobicity of the surface. On the other hand, the smooth surface of the cast films showed the small contact angle.

\section{Conclusions}

The synthesis of spherical particles was attained by the direct self-assembly of $\mathrm{P}(\mathrm{POA}-r-\mathrm{AA})$ and by the indirect self-assembly of $\mathrm{P}(\mathrm{POA}-r$-DAA) with the dicarboxylic acids in $\mathrm{scCO}_{2}$. The copolymers formed spherical particles with hundreds of nanometer-diameters in a heterogeneous state at pressures lower than the cloud point pressure. The formation of spherical particles was also dependent on the temperature. The formation of spherical particles could be optimized through varying the solvent quality by the manipulation of the $\mathrm{CO}_{2}$ pressure and temperature for the different copolymer compositions. The dynamic light scattering and ${ }^{1} \mathrm{H}$ NMR studies demonstrated that the nanospheres had the micellar structures consisting of the $\mathrm{CO}_{2}$-philic POA shells and the $\mathrm{CO}_{2}$-phobic AA or DAA cores including the main chain cores. The nanospheres had the superhydrophobicity based on the water-proof shells of the POA units. This study demonstrated that the nanospheres prepared by the self-assembly in $\mathrm{scCO}_{2}$ produced the superhydrophobic surfaces.

\section{References}

[1] Y. K. Ha, H. S. Song, H. J. Lee, and J. H. Kim, "Preparation of core particles for toner application by membrane emulsification," Colloids and Surfaces A, vol. 162, no. 1-3, pp. 289-293, 2000.

[2] L. A. Simpson, J. Robb, J. Banford, P. F. Dietz, and J. Temperley, "Composite pigmentary material," Eur Pat Appl EP 573150 A2 8 Dec: 14, 1993.

[3] D. S. Schlossman, "Method of coupling cosmetic materials and cosmetics containing coupled materials," US 5314683 A1 24 May: 12, 1994.

[4] B. Bohnel and D. L. Schlosser, "Aqueous, repositionable, high peel strength pressure sensitive adhesives," Eur Pat Appl EP 439941 A1 7 Aug: 11, 1991.

[5] S. Di and V. Frank, "Aqueous high performance contact adhesive containing microspheres," Eur Pat Appl EP 534393 A1 31 Mar: 9, 1993.

[6] K. A. Yoon and D. J. Burgess, "Effect of cationic surfactant on transport of model drugs in emulsion systems," Journal of Pharmacy and Pharmacology, vol. 49, no. 5, pp. 478-484, 1997.

[7] M. J. Lawrence, S. M. Lawrence, and D. J. Barlow, "Aggregation and surface properties of synthetic double-chain non-ionic surfactants in aqueous solution," Journal of Pharmacy and Pharmacology, vol. 49, no. 6, pp. 594-600, 1997.

[8] M. Zerfa and B. W. Brooks, "Experimental investigation of vinyl chloride drop behavior during suspension polymerization," Journal of Applied Polymer Science, vol. 65, no. 1, pp. 127-134, 1997. 
[9] G. Wang, M. Li, and X. Chen, "Inverse suspension polymerization of sodium acrylate," Journal of Applied Polymer Science, vol. 65, no. 4, pp. 789-794, 1997.

[10] Y. Chen and H. W. Yang, "Hydroxypropyl cellulose (HPC)stabilized dispersion polymerization of styrene in polar solvents: effect of reaction parameters," Journal of Polymer Science A, vol. 30, no. 13, pp. 2765-2772, 1992.

[11] D. Horak, F. Svec, and J. M. J. Frechet, "Preparation of colored poly(styrene-co-butyl methacrylate) micrometer size beads with narrow size distribution by dispersion polymerization in presence of dyes," Journal of Polymer Science A, vol. 33, pp. 2961-2968, 1995.

[12] H. Bamnolker and S. Marcel, "Dispersion polymerization of styrene in polar solvents: effect of reaction parameters on microsphere surface composition and surface properties, size and size distribution, and molecular weight," Journal of Polymer Science A, vol. 34, no. 10, pp. 1857-1871, 1996.

[13] M. B. Taylor, R. D. Gilbert, and V. T. Stannett, "Radiationinitiated inverse emulsion polymerization of vinylpyrrolidone," Journal of Applied Polymer Science, vol. 53, no. 10, pp. 1385-1390, 1994.

[14] F. Sun and E. Ruckenstein, "Preparation of high molecular weight monodisperse polystyrene latexes by concentrated emulsion polymerization," Journal of Applied Polymer Science, vol. 48, no. 7, pp. 1279-1288, 1993.

[15] C. S. Chern and Y. C. Chen, "Semibatch emulsion polymerization of butyl acrylate stabilized by a polymerizable surfactant," Polymer Journal, vol. 28, no. 7, pp. 627-632, 1996.

[16] J. B. McClain, D. E. Betts, D. A. Canelas et al., "Design of nonionic surfactants for supercritical carbon dioxide," Science, vol. 274, no. 5295, pp. 2049-2052, 1996.

[17] E. Buhler, A. V. Dobrynin, J. M. DeSimone, and M. Rubinstein, "Light-scattering study of diblock copolymers in supercritical carbon dioxide: $\mathrm{CO}_{2}$ density-induced micellization transition,” Macromolecules, vol. 31, no. 21, pp. 7347-7355, 1998.

[18] S. Zhou and B. Chu, "Self-assembly behavior of a diblock copolymer of poly(1-dihydroperfluorooctyl acrylate) and poly(vinyl acetate) in supercritical carbon dioxide," Macromolecules, vol. 31, no. 22, pp. 7746-7755, 1998.

[19] C. Baysal, B. Erman, and B. Chu, "Conformational features of poly(1-dihydroperfluorooctyl acrylate) and poly(vinyl acetate) diblock oligomers in supercritical carbon dioxide," Journal of Chemical Physics, vol. 114, no. 12, pp. 5444-5449, 2001.

[20] F. Triolo, A. Triolo, R. Triolo et al., "Critical micelle density for the self-assembly of block copolymer surfactants in supercritical carbon dioxide," Langmuir, vol. 16, no. 2, pp. 416-421, 2000.

[21] M. Nakano, M. Deguchi, K. Matsumoto, H. Matsuoka, and H. Yamaöka, "Self-assembly of poly(1,1-diethylsilabutane)block-poly(2-hydroxyethyl methacrylate) block copolymer. 1. Micelle formation and micelle-unimer-reversed micelle transition by solvent composition," Macromolecules, vol. 32, no. 22, pp. 7437-7443, 1999.

[22] E. D. Niemeyer and F. V. Bright, "The $\mathrm{pH}$ within PFPE reverse micelles formed in supercritical $\mathrm{CO}_{2}$," Journal of Physical Chemistry B, vol. 102, no. 8, pp. 1474-1478, 1998.

[23] D. C. Steytler and J. D. Holmes, "Aggregation and solubilisation in near critical $\mathrm{CO}_{2}$ studied by scattering methods," Current Opinion in Colloid and Interface Science, vol. 3, no. 3, pp. 299-304, 1998.
[24] E. Yoshida and A. Mineyama, "Synthesis of spherical particles by self-assembly of poly[2-(perfluorooctyl)ethyl acrylate-coacrylic acid] in supercritical carbon dioxide," Colloid and Polymer Science, vol. 286, no. 8-9, pp. 975-981, 2008.

[25] E. Yoshida and A. Nagakubo, "Convenient synthesis of microspheres by self-assembly of random copolymers in supercritical carbon dioxide," Colloid and Polymer Science, vol. 285, no. 4, pp. 441-447, 2007.

[26] E. Yoshida and A. Nagakubo, "Superhydrophobic surfaces of microspheres obtained by self-assembly of poly[2-(perfluorooctyl)ethyl acrylate-ran-2-(dimethylamino)ethyl acrylate] in supercritical carbon dioxide," Colloid and Polymer Science, vol. 285, no. 11, pp. 1293-1297, 2007.

[27] S. Kobayahshi, H. Uyama, I. Yamamoto, and Y. Matsumoto, "Preparation of monodispered poly(methyl methacrylate) particle in the size of mícron range," Polymer Journal, vol. 22, no. 8, pp. 759-761, 1990. 

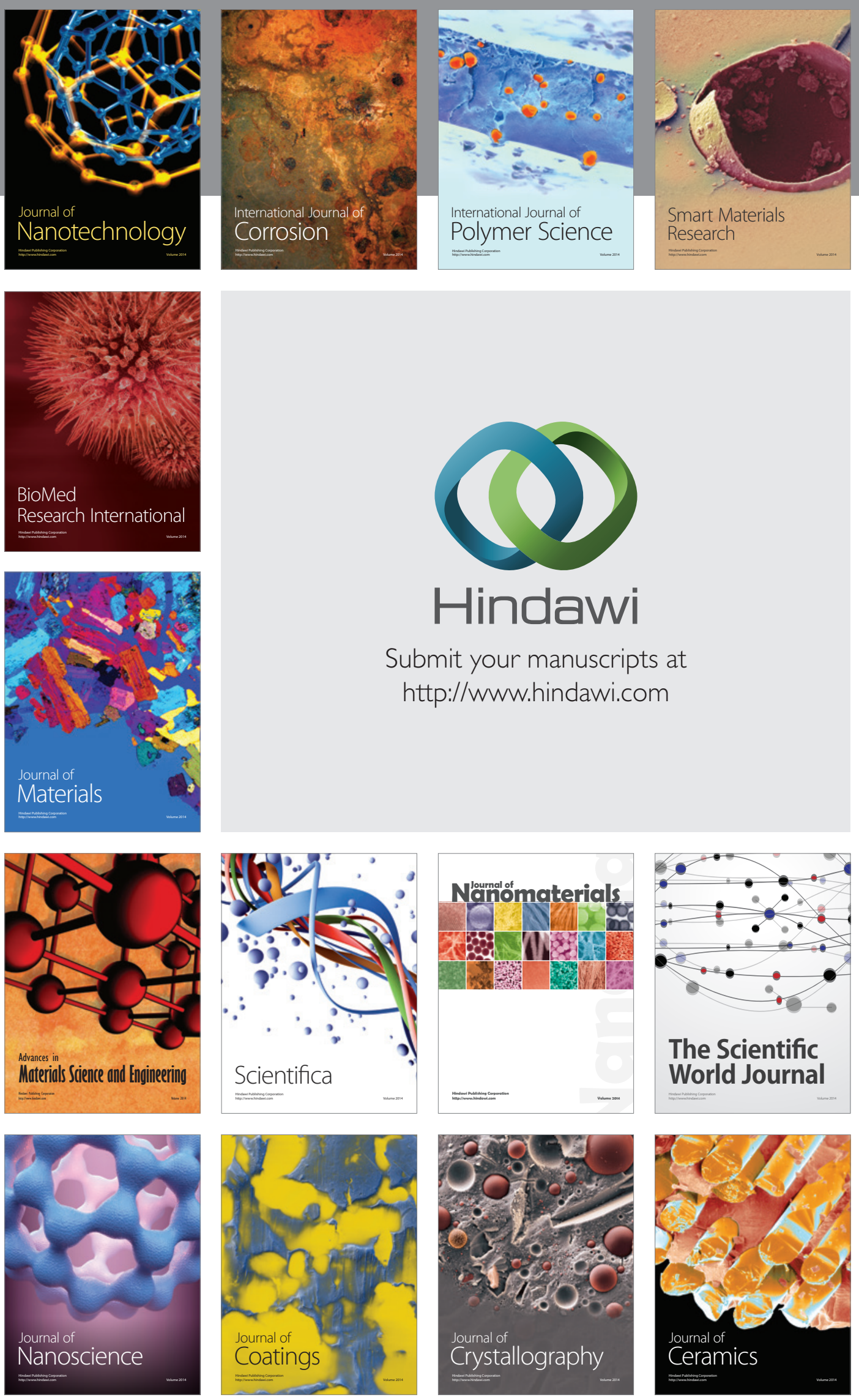

The Scientific World Journal

Submit your manuscripts at

http://www.hindawi.com

\section{World Journal}

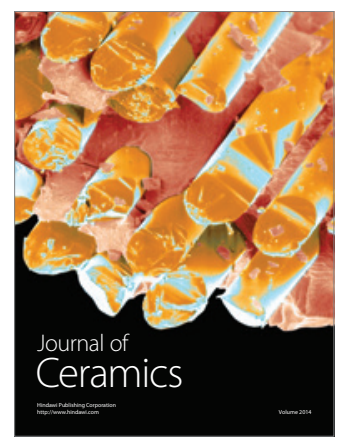

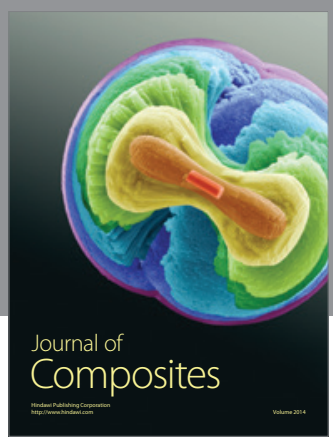
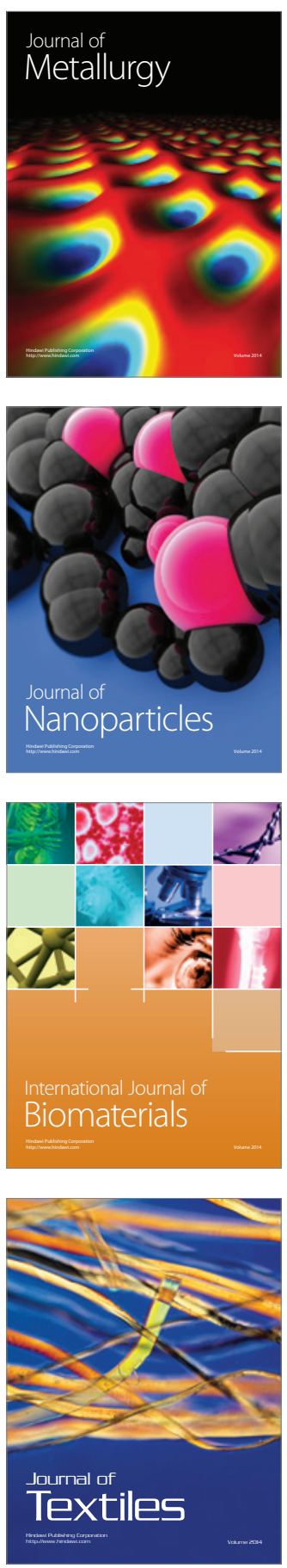